\title{
QUÍMICA E GÊNESE DE SOLOS DESENVOLVIDOS SOB VEGETAÇÃO DE RESTINGA NO ESTADO DE SÃO PAULO ${ }^{(1)}$
}

\author{
Maurício Rizzato Coelho ${ }^{(2)}$, Pablo Vidal-Torrado ${ }^{(3)}$, Xosé \\ Luiz Otero Pérez ${ }^{(4)}$, Vanda Moreira Martins ${ }^{(5)} \&$ Felipe \\ Macías Vázquez ${ }^{(4)}$
}

\begin{abstract}
RESUMO
As áreas arenosas e de solos pobres com vegetação característica das planícies costeiras brasileiras são genericamente denominadas de restinga. Os solos desses ambientes foram muito pouco estudados. Para este estudo, selecionaram-se áreas de restinga dos municípios paulistas de Cananeia, Ilha Comprida e Bertioga devido à existência de diferentes unidades sedimentares, de vegetação remanescente e de solos, representativos da planície costeira do Estado de São Paulo. Nesses locais foram descritos e amostrados 31 perfis, muitos deles em cronossequência, objetivando caracterizá-los quimicamente e convergir evidências analíticas para elucidação dos principais mecanismos envolvidos na gênese dos Espodossolos estes de ampla ocorrência no ecossistema restinga, componente do bioma Mata Atlântica nas planícies costeiras do Sudeste do Brasil. Para isso, foram utilizados procedimentos analíticos de rotina para fins de levantamento e classificação de solos, bem como de dissoluções seletivas dos elementos Fe (ditionito-citrato, oxalato e pirofosfato) e $\mathrm{Al}$ (ditionito-citrato, oxalato, pirofosfato, $\mathrm{CuCl}_{2}, \mathrm{LaCl}_{3}$ e $\mathrm{KCl}$ ), os quais permitiram as seguintes interpretações: (a) a maioria dos solos de restinga estudados mostra-se de textura essencialmente arenosa e predominância de areia fina, com baixas soma e saturação por bases, reação extrema a fortemente ácida, capacidade de troca de cátions dependente da matéria orgânica e dominada por Al trocável, havendo aumento do conteúdo e estabilidade de carbono orgânico em profundidade. Esses atributos refletem a influência tanto do material de origem como do processo pedogenético predominante nesses ambientes: a podzolização; (b) o Al é o principal cátion envolvido na podzolização e suas formas
\end{abstract}

(1) Parte da Tese de Doutorado do primeiro autor apresentada à Escola Superior de Agricultura "Luiz de Queiroz" - ESALQ/USP. Realizada com auxílio da CAPES e FAPESP. Recebido para publicação em agosto de 2009 e aprovado em outubro de 2010.

${ }^{(2)}$ Pesquisador do Centro Nacional de Pesquisa em Solos, Embrapa Solos. Rua Jardim Botânico 1024, Jardim Botânico, CEP 22460000 Rio de Janeiro (RJ). E-mail: mauricio@cnps.embrapa.br

(3) Professor do Departamento de Ciência do Solo, Escola Superior de Agricultura "Luiz de Queiroz" - ESALQ/USP. Caixa Postal 09, CEP 13418-900 Piracicaba (SP). Bolsista do CNPq. E-mail: pablo@esalq.usp.br

(4) Professor do Departamento de Edafología de la Universidad de Santiago de Compostela. Campus Universitario Sur. Faculdad de Bioloxía. Espanha. E-mail: xl.otero@usc.es; felipe.macias.vasquez@usc.es

(5) Professora do Curso de Geografia da Universidade Estadual do Oeste do Paraná - UNIOESTE. Campus de Marechal Cândido Rondon, Rua Pernambuco 1777, Centro, CEP 85960-000 Marechal Cândido Rondon (PR). E-mail: mmvanda@hotmail.com 
ativas são: complexos de Al-húmus e compostos inorgânicos pouco cristalinos; (c) alguns horizontes espódicos com subscrito "s" (Bs, Bhs e Bsm), situados na base de perfis bem drenados, detêm os maiores valores de saturação por $\mathrm{Al}$ no húmus e estabilidade da interação carbono-metal entre todas as amostras e horizontes estudados; (d) existe estreita relação entre a idade dos Espodossolos e os atributos químicos analisados: os mais antigos (Cananeia) diferenciam-se dos demais quer pelos maiores conteúdos médios de $\mathrm{C}$ e de $\mathrm{Al}$ ativo ( $\mathrm{Al}$ trocável, $\mathrm{Al}$ oxalato e $\mathrm{Al}$ pirofosfato), quer pela maior estabilidade da interação Al-húmus nos horizontes espódicos; e (e) estes se formaram predominantemente às expensas dos eluviais, com atuação de processos de queluviação de Al-húmus e sua imobilização em profundidade à medida que há saturação do elemento nos complexos organometálicos que migram no perfil.

Termos de indexação: dissoluções seletivas, ditionito-citrato, oxalato, pirofosfato, $\mathrm{CuCl}_{2}, \mathrm{LaCl}_{3}$, podzolização, Espodossolos.

\section{SUMMARY: CHEMISTRY AND GENESIS OF SOILS DEVELOPED UNDER RESTINGA VEGETATION IN SÃO PAULO STATE, BRAZIL}

Restinga is a term currently used for the vegetation on the poor and sandy soils of the coastal plains of Brazil. The soils of these environments have been poorly studied. The counties Cananeia, Ilha Comprida and Bertioga were selected for this research due to the representativeness of the environmental conditions of the state of São Paulo. In these environments 31 soil profiles were described and sampled, many of them in chronosequences. The samples were characterized chemically and analytical evidence converged to elucidate the main mechanisms involved in the genesis of Spodosols, which are of widespread occurrence in the Restinga environments of Sao Paulo State and across Brazil. For these purposes, routine analytical procedures for soil survey and classification were used, as well as selective dissolution of the elements $\mathrm{Fe}$ (dithionite-citrate, oxalate and pyrophosphate) and Al (dithionite-citrate, oxalate, pyrophosphate, $\mathrm{CuCl}, \mathrm{LaCl}_{3}$ and $\mathrm{KCl}$ ), resulting in the following interpretations: (a) most studied Restinga soils had a low sum of bases and base saturation, strong to extreme acidity, cation exchange capacity depending on the organic matter and dominated by exchangeable Al, with increasing content and stability of organic carbon with depth. These properties reflect the influence of both the parental material and the main predominant pedogenetic process in these environments: podzolization; (b) Al is the main cation in the podzolization process. The reactive forms of this element are Al-humus complexes and poorly crystalline inorganic compounds; (c) Al-humus saturation is highest in some spodic horizons with "s"subscript (Bs, Bhs and Bsm) located at the base of well-drained profiles and the metalcarbon interaction among all samples and horizons studied is stable; (d) there is a close relationship between Spodosol age and the chemical properties analyzed: the oldest (Cananéia) are differentiated from the others by higher mean content of $C$ and active Al (exchangeable Al, Aloxalate and Alpyrophosphate) and greater stability of the interaction in Al-humus of spodic horizons; and (e) the spodic horizons studied were formed mainly at the expense of eluvial horizons and queluviation processes of Al-humus and its immobilization in depth through Al saturation in organo-metallic complexes migrating in the profile.

Index terms: selective dissolution, dithionite-citrate, oxalate ammonium, Na pyrophosphate, $\mathrm{CuCl}_{2}, \mathrm{LaCl}_{3}$, podzolization, Spodosol.

\section{INTRODUÇÃO}

Os Espodossolos são os solos predominantes nos ambientes de restinga (Oliveira et al., 1992). As principais teorias relativas aos processos de podzolização foram revisadas por Sauer et al. (2007). Segundo esses autores, as hipóteses sobre a formação desses solos, envolvendo mecanismos de mobilização e translocação de compostos, podem ser resumidas em três principais teorias: (1) formação de complexos solúveis em água de ácidos orgânicos com íons Fe, $\mathrm{Al}$ e $\mathrm{Si}$; (2) redução do Fe por ácidos orgânicos e migração de complexos organometálicos; e (3) translocação de $\mathrm{Al}$, Si e Fe como coloides inorgânicos. Assim, esses elementos e a matéria orgânica são lixiviados do topo do solo e, pelo menos em parte e por algum motivo, imobilizados e acumulados no subsolo (De Coninck, 1980). A continuidade desses processos conduz à 
diferenciação de horizonte eluvial (perda) e iluvial (acumulação), os quais finalmente resultam na formação dos Espodossolos (Sauer et al., 2007).

A satisfatória caracterização química dos horizontes B espódicos dos Espodossolos requer o uso de pelo menos dois extratores: oxalato, para avaliar o conteúdo total (orgânico e inorgânico) de Al, Fe e Si nos produtos de intemperismo, e pirofosfato, para determinar as formas orgânicas de $\mathrm{Al}$ e $\mathrm{Fe}$ (Farmer et al., 1983). Como esses elementos estão predominantemente associados aos materiais orgânicos nos horizontes espódicos, o pirofosfato foi considerado, no passado, o melhor extrator para materiais amorfos desses horizontes (Mokma, 1983). No entanto, resultados apresentados por Jeanroy \& Guillet (1981), Pagé \& Kimpe (1989), Paterson et al. (1993) e Kaiser \& Zech (1996) questionaram a efetiva utilidade do uso deste reagente na caracterização dos solos, uma vez que ele pode extrair outras formas que não apenas $\mathrm{Al}$ e $\mathrm{Fe}$ complexados à matéria orgânica. Parfitt \& Childs (1988) e Schuppli et al. (1983), por outro lado, consideram que os resultados de pirofosfato são reproduzíveis desde que o método utilize determinados procedimentos analíticos. Em alguns solos, particularmente Espodossolos e Andossolos, Higashi (1983) constatou que esse extrator ofereceu boas indicações do conteúdo de $\mathrm{Al}$ nos complexos Al-húmus.

Os critérios químicos para definição de horizonte espódico têm variado à medida que pesquisas evoluem no que diz respeito ao extrator mais adequado para materiais amorfos (McKeague et al., 1971). Nesse contexto, tem-se sugerido que, para a adequada caracterização do $\mathrm{Al}$ complexado à matéria orgânica, extratores não tamponados de cloro, como $\mathrm{CuCl}_{2}$ (Juo \& Kamprath, 1979; Hargrove \& Thomas, 1981) e $\mathrm{LaCl}_{3}$ (Bloom et al., 1979), podem dar melhores resultados (Oates \& Kamprath, 1983), em vista da comprovada falta de seletividade do extrator pirofosfato para determinados solos e horizontes. García-Rodeja et al. (2004) utilizaram esses extratores não tamponados, juntamente com o pirofosfato e $\mathrm{KCl}$, a fim de avaliar a estabilidade da interação Al-húmus. Segundo esses autores, a seguinte ordem decrescente de estabilidade da associação metal-húmus pode ser obtida e quantificada subtraindo as diferentes formas de $\mathrm{Al}$ do solo: $\mathrm{Al}_{\mathrm{p}}-\mathrm{Al}_{\mathrm{Cu}}>\mathrm{Al}_{\mathrm{Cu}}-\mathrm{Al}_{\mathrm{La}}>\mathrm{Al}_{\mathrm{La}}-\mathrm{Al}_{\mathrm{K}}$, sendo os subscritos $\mathrm{p}$, $\mathrm{Cu}$, La e K referentes aos extratos obtidos com pirofosfato de sódio (p), $\mathrm{CuCl}_{2}(\mathrm{Cu}), \mathrm{LaCl}_{3}(\mathrm{La})$ e $\mathrm{KCl}(\mathrm{K})$, respectivamente.

Caracterizações químicas de solos sob vegetação de restinga no Brasil, com ênfase na gênese dos Espodossolos, podem ser encontradas nos trabalhos de Gomes (1995) no Estado do Rio de Janeiro e Rossi (1999) e Gomes (2005) em São Paulo. Esses estudos abarcam pequenas extensões geográficas e, por consequência, podem ser restritos na avaliação das diferentes feições, atributos e processos genéticos envolvidos na formação dos horizontes espódicos e Espodossolos.
O presente trabalho lança mão de 31 perfis de solos, a maioria descritos e amostrados em cronossequência em diferentes localidades geológica e geomorfologicamente representativas das restingas paulistas, a fim de caracterizar quimicamente seus solos, com ênfase nos Espodossolos, e auxiliar no entendimento dos mecanismos envolvidos na sua gênese. Para isso, foram realizados procedimentos de dissoluções seletivas do $\mathrm{Fe}$ e $\mathrm{Al}$ comumente utilizados nos estudos de caracterização e gênese de Espodossolos, como ditionito-citrato (DC), oxalato e pirofosfato, além da avaliação da interação do Al-húmus por meio de cloretos não tamponados $\left(\mathrm{CuCl}_{2}, \mathrm{LaCl}_{3}\right.$ e $\left.\mathrm{KCl}\right)$. Análises de rotina para fins de levantamento e classificação de solos complementam os procedimentos analíticos aqui utilizados no estudo dos solos sob vegetação de restinga.

\section{MATERIAL E MÉTODOS}

\section{Meio físico}

Foram descritos perfis e coletadas amostras de solos em três municípios do litoral do Estado de São Paulo: Bertioga, Cananeia (Ilha de Cananeia) e Ilha Comprida (Figura 1). O clima do litoral do Estado de São Paulo é do tipo Af, segundo a classificação climática de Köppen, com precipitação pluvial média anual de 1.800 a $2.000 \mathrm{~mm}$ e médias de temperaturas mínimas de $19^{\circ} \mathrm{C}$ e de temperaturas máximas de $27^{\circ} \mathrm{C}$ (Melo \& Mantovani, 1994). A geologia dos locais estudados é composta por sedimentos arenosos quaternários de origem marinha (Petri \& Fúlfaro, 1970; Suguio \& Martin, 1978a). Neles desenvolveu-se uma vegetação de floresta tropical úmida, genericamente denominada de vegetação de restinga - ecossistema característico das zonas costeiras da região Sudeste do Brasil (Suguio $\&$ Tessler, 1984) e que compõe o bioma Mata Atlântica. Os solos predominantes desses ambientes pertencem às classes dos Espodossolos e Neossolos Quartzarênicos (Oliveira et al., 1992); muitas vezes, estes últimos apresentam incipiente processo de podzolização (Gomes, 2005).

Conforme levantamento geológico realizado por Suguio \& Martin (1978b), na planície costeira de Bertioga predominam depósitos holocênicos de várias origens, ocorrendo remanescentes de terraços marinhos pleistocênicos somente nas proximidades do rio Itapanhaú.

Ilha Comprida, localizada no litoral sul do Estado de São Paulo (Figura 1), tem $63 \mathrm{~km}$ de comprimento por até $5 \mathrm{~km}$ de largura (Nascimento-Júnior, 2006). É constituída predominantemente de sedimentos arenosos quaternários, com presença de dunas holocênicas. Das sequências estudadas, é a que apresenta o material de origem mais jovem; na Ilha de Cananeia, encontra-se o mais antigo (Coelho, 2008; Martins, 2009). Esta também é predominantemente 


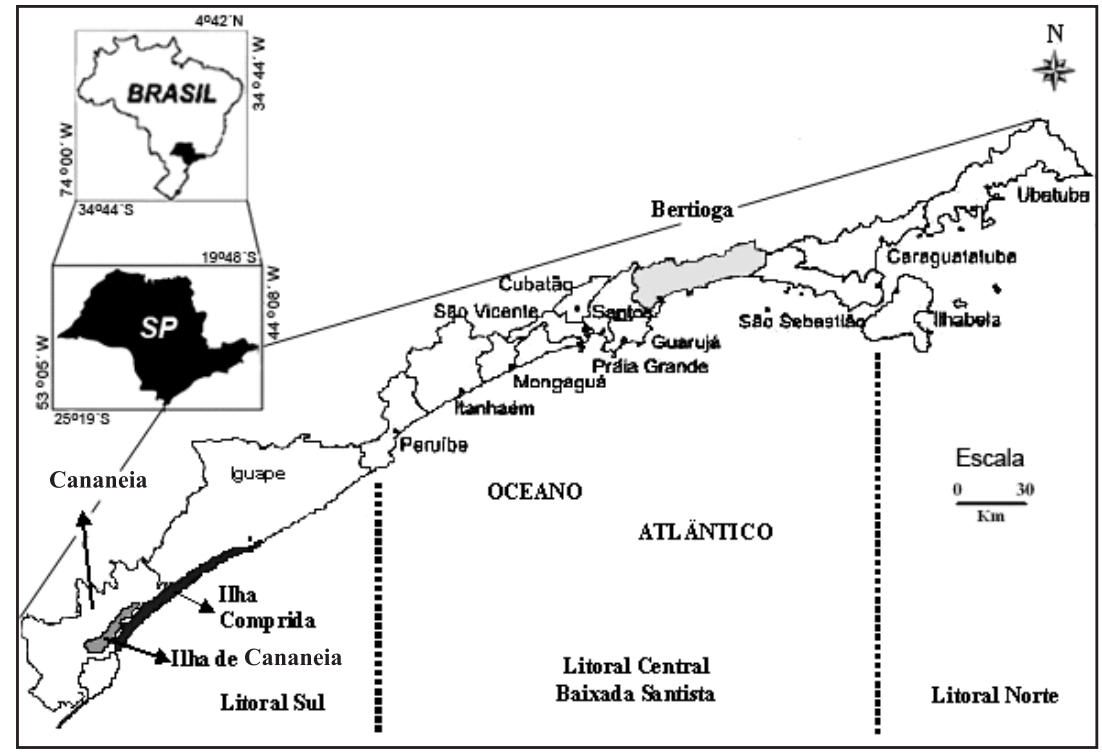

Figura 1. Localização dos municípios de Bertioga, Cananeia e Ilha Comprida, no litoral do Estado de São Paulo.

composta de sedimentos arenosos quaternários de idade pleistocênica (Suguio et al., 1999).

\section{Trabalhos de campo}

Os trabalhos de campo consistiram em tradagens, observações de barrancos e trincheiras, a fim de selecionar os locais de amostragem. Estes consistiram de 31 perfis de solos representativos das unidades geomorfoestratigráficas locais: 27 são Espodossolos e quatro classificados como Neossolos Quartzarênicos. No município de Bertioga, 13 perfis foram coletados em cronossequência (perfis P1 a P13), dos mais antigos (pleistocênicos) para os mais jovens (holocênicos a atuais). Em Ilha Comprida (10 perfis; P17 a P26) e Cananeia (5 perfis; P27 a P31) os solos foram descritos e amostrados transversalmente ao comprimento das ilhas. Os perfis foram descritos e amostrados conforme Santos et al. (2005), e os solos, classificados segundo Embrapa (2006). A descrição morfológica e a localização dos perfis estudados são encontradas em Coelho (2008).

\section{Procedimentos analíticos}

\section{Análises de rotina}

No laboratório, as amostras de solo foram secas ao ar, destorroadas com um martelo de borracha, quando necessário, e passadas em peneira n. ${ }^{\circ} 10$ (malha de $2 \mathrm{~mm}$ ), obtendo-se a fração terra fina seca ao ar (TFSA), onde foram realizadas as análises químicas e granulométricas. Esta última foi realizada pelo método do densímetro, utilizando hidróxido de sódio $0,1 \mathrm{~mol} \mathrm{~L}^{-1}$ como agente dispersante (Embrapa, 1997).

Foram as seguintes análises químicas e procedimentos analíticos utilizados (Embrapa, 1997): o pH foi determinado em água (potenciômetro), utilizando relação solo:solução 1:2,5 após agitação e repouso de uma hora; o carbono orgânico (C), por oxidação com dicromato de $\mathrm{K}$. Os cátions $\mathrm{Ca}^{2+}, \mathrm{Mg}^{2+}$ e $\mathrm{Al}^{3+}$ foram extraídos com solução $\mathrm{KCl} 1 \mathrm{~mol} \mathrm{~L}^{-1}$. A extração do $\mathrm{H}+\mathrm{Al}$ foi realizada com solução de acetato de cálcio $0,5 \mathrm{~mol} \mathrm{~L}^{-1}$ a pH 7,0. Os elementos $\mathrm{Na}^{+}$e $\mathrm{K}^{+}$ foram extraídos com solução de $\mathrm{H}_{2} \mathrm{SO}_{4} 0,0125 \mathrm{~mol} \mathrm{~L}^{-1}$

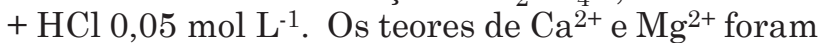
determinados por espectroscopia de absorção atômica; $\mathrm{K}^{+}$e $\mathrm{Na}^{+}$, por fotometria de chama; $\mathrm{Al}^{3+} \mathrm{e} \mathrm{H}+\mathrm{Al}$ por titulometria.

\section{Dissoluções seletivas}

Foram utilizados os seguintes procedimentos de dissolução seletiva para a extração de $\mathrm{Al}$ e, ou, Fe: (a) Extração do Fe e Al com oxalato ácido de amônio, de acordo com Buurman et al. (1996): relação solo:solução de 1:50, agitando por $4 \mathrm{~h}$ no escuro. A suspensão foi centrifugada por $15 \mathrm{~min}$ a $2.500 \mathrm{rpm}$, com quatro gotas de "superfloc", e o sobrenadante foi filtrado em papel-filtro lavado em ácido (7-11 $\mu \mathrm{m}$ de diâmetro de poro); (b) Extração do Fe e Al com pirofosfato de sódio $0,1 \mathrm{~mol} \mathrm{~L}^{-1}$ (pH 10): relação solo:solução 1:100, agitando por 16 h (Buurman et al., 1996). Após adição de quatro gotas de "superfloc", procedeu-se à centrifugação e filtragem, conforme os procedimentos supracitados; (c) Extração do Fe com ditionito-citrato de sódio (DC): relação solo:solução 1:125, agitando por 16 h, segundo método proposto por Holmgren (1967). Os procedimentos seguintes foram semelhantes aos anteriormente relatados; (d) Extração do $\mathrm{Al}$ com $\mathrm{CuCl}_{2}$ $0,5 \mathrm{~mol} \mathrm{~L}^{-1}\left(\mathrm{pH} 3 ; \mathrm{Al}_{\mathrm{Cu}}\right): 5 \mathrm{~g}$ de solo foram agitados durante 5 min com $50 \mathrm{~mL}$ da solução extratora. Após agitação, a suspensão permaneceu em repouso durante $12 \mathrm{~h}$, seguida de nova agitação durante $30 \mathrm{~min}$ e filtragem em papel-filtro lavado em ácido. Lavou-se o 
solo contido no papel-filtro com $\mathrm{CuCl}_{2}$ até completar o volume para $100 \mathrm{~mL}$ (Juo \& Kamprath, 1979); (e) Extração do $\mathrm{Al}$ com $\mathrm{LaCl}_{3} 0,33 \mathrm{~mol} \mathrm{~L}^{-1}\left(\mathrm{pH} 4 ; \mathrm{Al}_{\mathrm{La}}\right)$ : $10 \mathrm{~g}$ de solo foram agitados durante $2 \mathrm{~h}$ com $50 \mathrm{~mL}$ da solução extratora. A suspensão foi filtrada utilizando papel-filtro lavado em ácido, e o solo nele retido foi lavado com $\mathrm{LaCl}_{3}$ até completar o volume para $100 \mathrm{~mL}$ (Hargrove \& Thomas, 1981); (f) Extração do $\mathrm{Al}$ com KCl $1 \mathrm{~mol} \mathrm{~L}^{-1}\left(\mathrm{pH} 5 ; \mathrm{Al}_{\mathrm{K}}\right): 5$ g de solo foram agitados durante $5 \mathrm{~min}$ com $50 \mathrm{~mL}$ da solução extratora. Após agitação, procedeu-se imediatamente à filtragem da suspensão em papel-filtro lavado em ácido (Raij et al., 2001).

Alumínio e Fe nos extratos foram determinados por espectroscopia de absorção atômica. Os resultados apresentados para esses elementos representam a média das análises realizadas em duplicata, que diferiram entre si em menos de $10 \%$.

\section{RESULTADOS E DISCUSSÃO}

\section{Química de rotina e estabilidade da interação Al-húmus}

No quadro 1 são mostrados os dados químicos e granulométricos de 20 perfis selecionados. Observamse tendências similares àquelas já descritas por Gomes (2005) na Ilha do Cardoso (SP) e Rossi (1999) e Moreira (2007) para os solos sob vegetação de restinga do município de Bertioga: textura essencialmente arenosa, baixos valores de soma (SB) e saturação por bases (V), dominância de solos extrema a fortemente ácidos, capacidade de troca de cátions (T) altamente dependente da matéria orgânica (Figura 2) e dominada por Al trocável, sobretudo nos horizontes espódicos. Esses atributos refletem a influência tanto do material de origem como do processo pedogenético predominante nesses ambientes: a podzolização. Enquanto o primeiro, originalmente quartzoso e com baixos conteúdos de minerais facilmente intemperizáveis, imprime a pobreza em nutrientes e a textura arenosa aos solos, praticamente destituídos de argila, e predominância da fração areia fina e muito fina bem selecionada (Villwock, 2005), os atributos mais marcantes e relativos à podzolização são o expressivo acúmulo de $\mathrm{C}$ e $\mathrm{Al}$ em profundidade, típico dos Espodossolos. Em consequência, os valores de SB e de V são consideravelmente superiores nos horizontes A (SB mínimo, máximo e média de 2,20, 36,1 e 1,91 $\mathrm{mmol}_{\mathrm{c}} \mathrm{kg}^{-1}$; V mínimo, máximo e média de 3,87 e $22 \%$, respectivamente) comparativamente aos B espódicos (SB mínimo, máximo e média de 0,0, 17,49 e 5,97 $\mathrm{mmol}_{\mathrm{c}} \mathrm{kg}^{-1}$; V mínimo, máximo e média de 0,100 e $11 \%$, respectivamente), uma vez que os cátions básicos $\left(\mathrm{Ca}^{2+}\right.$, $\mathrm{Mg}^{2+}, \mathrm{K}^{+}$e $\mathrm{Na}^{+}$) são constantemente incorporados aos horizontes superficiais via ciclagem de nutrientes e não se acumulam nos horizontes espódicos, dominados por Al trocável (Quadro 1).

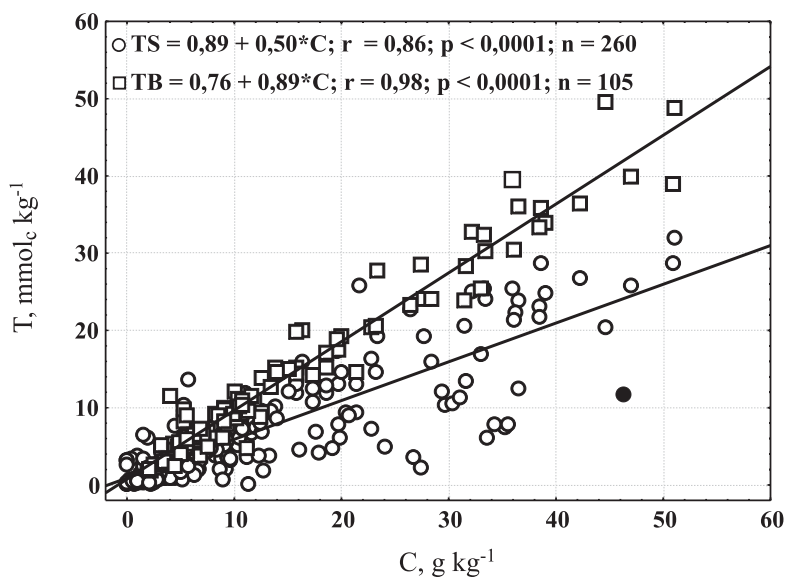

Figura 2. Relação entre a capacidade de troca de cátions (T) e o carbono orgânico (C). TS referese a todos os horizontes e perfis estudados; TB, apenas aos horizontes espódicos.

Nos Espodossolos, em geral, os valores de $\mathrm{pH}$ tendem a ser mais elevados nos horizontes E, por serem lavados e praticamente destituídos de material orgânico (Gomes et al., 1998), a mais provável fonte de acidez nesses solos; daí os valores mínimo e máximo e a média de $\mathrm{pH}$ nos horizontes espódicos da sequência de Ilha Comprida - respectivamente de 4,3, 6,0 e 5,0 - serem superiores àqueles de Bertioga $(3,1,5,3$ e 4,4) e Cananeia (3,7, 5,2 e 4,4), já que os conteúdos de C acompanham essas tendências (Quadro 1). De fato, a figura 3a evidencia que a sequência de Ilha Comprida mostra os horizontes B espódicos com os menores conteúdos de $\mathrm{C}$ (mínimo, máximo e a média, respectivamente, de 2,01, 12,40 e 6,13 $\mathrm{g} \mathrm{kg}^{-1}$ ), comparativamente aos de Bertioga (2,19, 51,00 e 15,07 $\left.\mathrm{g} \mathrm{kg}^{-1}\right)$ e Cananeia $\left(5,56,50,94 \mathrm{e} \mathrm{22,08} \mathrm{g} \mathrm{kg}^{-1}\right)$. Esta última apresenta os sedimentos e Espodossolos mais antigos estudados, enquanto em Ilha Comprida encontram-se os mais recentes (Coelho et al., 2010a), sugerindo que o tempo pode ser um fator responsável pelo maior acúmulo (Figura 3a) e estabilidade (Figura 3b) do C nos Espodossolos - fato já constatado por Skjemstad et al. (1992a) em solos semelhantes sob dunas na Austrália. Segundo esses autores, os horizontes espódicos mais antigos mostraram dominância de matéria orgânica com estruturas aromáticas, estáveis, as quais são fortemente associadas e floculadas por Al, imprimindo coloração negra aos horizontes. A maior proporção relativa de horizontes ortstein nos solos de Cananeia comparativamente à das demais sequências estudadas - os quais manifestam os maiores graus de consistência seca (extremamente dura) e cimentação (fortemente cimentado), predominância de colorações negras (Coelho et al., 2010a) e os mais elevados teores das diferentes formas de $\mathrm{Al}$ no perfil entre todos os estudados (Figura 3c; Quadro 1) - sugere similaridades com as constatações de Skjemstad et al. (1992a), de forma que permanecem intactos nas paisagens atuais e apenas naquelas mais antigas, como evidenciado por Coelho et al. (2010a) para a área estudada. A 
figura 3b ajuda a corroborar as assertivas anteriores: os horizontes espódicos dos solos de Cananeia mostram os mais elevados teores médios de todas as formas de $\mathrm{Al}$ que expressam sua estabilidade da interação com a matéria orgânica do solo, sendo suas formas mais estáveis $\left(\mathrm{Al}_{\mathrm{p}}-\mathrm{Al}_{\mathrm{Cu}}\right)$, dominantes. Inversamente, os de Ilha Comprida, formados nos sedimentos mais recentes, detêm não só os menores conteúdos das formas mais estáveis da interação $\mathrm{Al}$-húmus $\left(\mathrm{Al}_{\mathrm{p}}-\mathrm{Al}_{\mathrm{Cu}}\right)$, como a menor amplitude de variação entre aquelas mais $\left(\mathrm{Al}_{\mathrm{p}}-\mathrm{Al} \mathrm{Cu}\right)$ e menos $\left(\mathrm{Al}_{\mathrm{La}}-\mathrm{Al}_{\mathrm{K}}\right)$ estáveis (Figura $3 \mathrm{~b}$ ), sugerindo que o tempo é um fator que também contribui para a estabilidade da interação metal-carbono.

\section{Dissoluções seletivas \\ Grau de saturação do $\mathrm{Al}$ no húmus $\left(\mathrm{Al}_{\mathrm{p}} / \mathrm{C}\right)$}

Multiplicando a relação $\mathrm{Al}_{\mathrm{p}} / \mathrm{C}$ por 100 , tem-se a porcentagem de saturação por Al na matéria orgânica dos solos estudados. Para os horizontes superficiais esse valor é baixo (mínimo de 0,11; máximo de 12,04; média de 1,89 \%) e, em média, muito inferior àquele
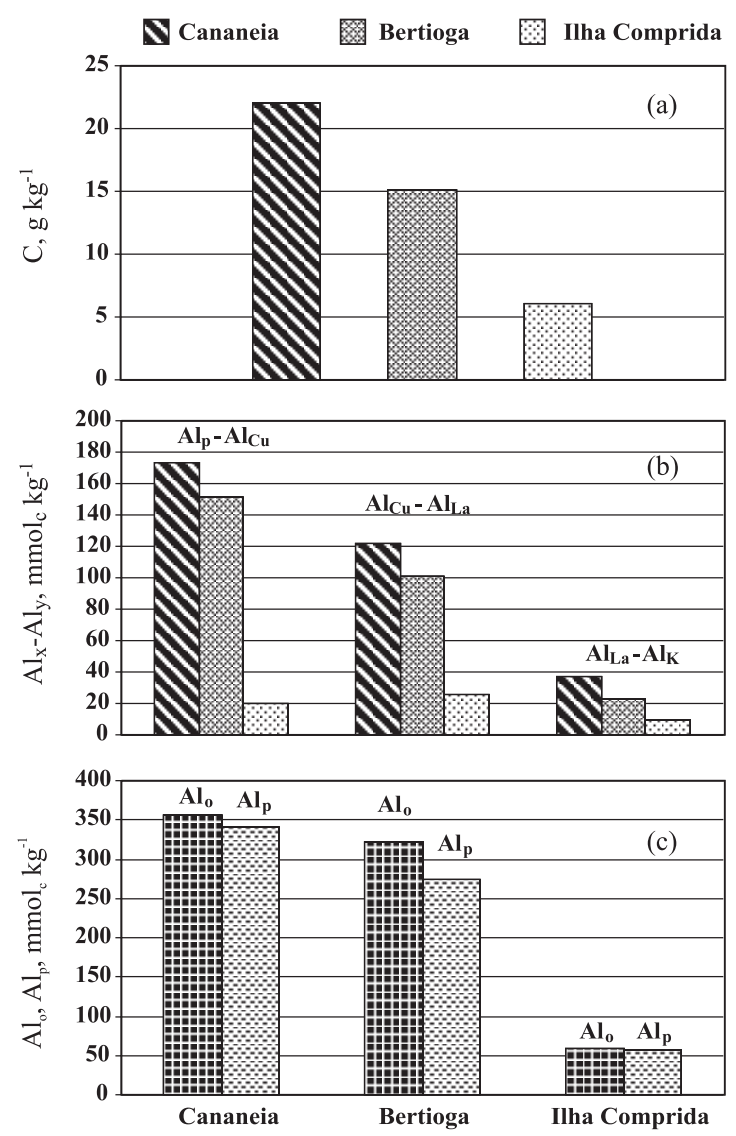

Figura 3. Conteúdos médios de C (a); formas de $\mathrm{Al}$ (média) associado à matéria orgânica com diferentes graus de estabilidade - os símbolos $x$ e y da subtração $\mathrm{Al}_{\mathrm{x}}-\mathrm{Al}_{\mathrm{y}}$ estão especificados acima de cada conjunto de três barras no gráfico (b); e teores médios de alumínio extraído com oxalato $\left(\mathrm{Al}_{\mathrm{o}}\right)$ e pirofosfato $\left(\mathrm{Al}_{\mathrm{p}}\right)(\mathrm{c})$ de horizontes espódicos. dos horizontes espódicos (mínimo de 2,21; máximo de 68,11; média de 19,43\%), o que pode ser devido ao menor grau de humificação da matéria orgânica dos horizontes superficiais em relação aos subsuperficiais. A variação significativa dessa relação para os horizontes espódicos é condizente com a sua diversidade morfológica (Coelho et al., 2010a) e química observada (Quadro 1) e deve refletir as condições ambientais em que foram formados (Coelho et al., 2010b). De fato, os maiores valores foram constatados para os horizontes espódicos Bs e C (Quadro 1), geralmente situados na base dos perfis bem drenados, fato também relatado por Jansen et al. (2005) e Mokma \& Buurman (1982) para Espodossolos boreais, indicando que a alta saturação por $\mathrm{Al}$ pode estar relacionada às boas condições de drenagem e, ou, ao tipo de matéria orgânica e, consequentemente, aos processos envolvidos na formação de tais horizontes.

\section{Fatores químicos envolvidos na diferenciação entre os horizontes espódicos}

\section{Alumínio}

Em termos gerais, os horizontes Bs, Bhs e Bsm dos perfis analisados, facilmente identificados no campo pela coloração em tons amarelados, comparativamente aos horizontes Bh, caracterizam-se pelos mais baixos conteúdos de carbono orgânico e maior relação $\mathrm{Al}_{\mathrm{p}} / \mathrm{C}$ observados, maior estabilidade da interação Alhúmus, mais elevados valores de $\mathrm{pH}$ e das diferentes formas de Fe (Quadro 1), condições químicas significativamente diferenciadas daquelas dos horizontes Bh. Esses resultados indicam que esses horizontes com subscrito "s" foram formados em condições ambientais diferenciadas e, consequentemente, diferentes mecanismos de podzolização podem ter atuado no desenvolvimento de um mesmo perfil ou entre os diferentes perfis estudados, basicamente condicionados pela presença ou ausência de hidromorfismo e por variações nos valores de $\mathrm{pH}$. Esses fatores, por sua vez, definem a permanência do elemento Fe nos solos estudados (hidromorfismo), bem como o tipo de interação dos metais (Fe e Al) com os demais componentes do sistema (pH).

A influência dos fatores químicos na formação e composição dos horizontes espódicos Bs, Bsm e Bhs bem drenados foi evidenciada por Coelho et al. (2010b) para os solos da área. Esses autores identificaram a presença de materiais inorgânicos de $\mathrm{Al}$ pouco cristalinos na maioria desses horizontes devido às condições químicas favoráveis, predominantemente valores de $\mathrm{pH}$ próximos ou acima de 5, o que propiciou a sua formação em detrimento da complexação do elemento à matéria orgânica do solo (Shoji et al., 1982; Shoji \& Fujiwara, 1984). Esses maiores valores de $\mathrm{pH}$, por sua vez, estão diretamente relacionados aos menores conteúdos de C, sobretudo nos horizontes Bs, comparativamente aos demais horizontes espódicos, já que a matéria orgânica é a principal responsável pela acidez dos solos estudados (Figura 4). 
Quadro 1. Dados químicos e granulométricos de perfis selecionados

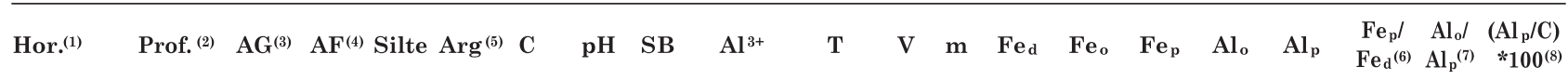

Bertioga - Perfil P1: Neossolo Quartzarênico órtico típico, A moderado, excessivamente drenado

\begin{tabular}{|c|c|c|c|c|c|c|c|c|c|c|c|c|c|c|c|c|c|c|c|c|}
\hline $\mathrm{A} 1$ & $0-8$ & 106 & 830 & 44 & 20 & 19,83 & 4,2 & 13,04 & 9,10 & 65,04 & 20 & 41 & 0,83 & 0,62 & 1,02 & 0,22 & 0,32 & 1,2 & 0,7 & 1,61 \\
\hline A2 & 8- 25 & 90 & 812 & 78 & 20 & 17,57 & 4,0 & 9,53 & 10,40 & 72,33 & 13 & 52 & 1,61 & 1,31 & 1,37 & 0,44 & 0,54 & 0,8 & 0,8 & 3,07 \\
\hline $\mathrm{AC}$ & $25-38$ & 82 & 836 & 62 & 20 & 9,69 & 4,5 & 8,52 & 7,10 & 55,72 & 15 & 45 & 2,43 & 2,31 & 2,27 & 1,19 & 1,17 & 0,9 & 1,0 & 12,07 \\
\hline CA & $38-84$ & 80 & 828 & 72 & 20 & 8,18 & 4,8 & 8,27 & 2,80 & 53,47 & 15 & 25 & 2,73 & 2,58 & 2,96 & 3,35 & 3,59 & 1,1 & 0,9 & 43,84 \\
\hline C1 & $84-140$ & 60 & 854 & 66 & 20 & 3,94 & 4,9 & 8,27 & 2,80 & 35,47 & 23 & 25 & 1,56 & 1,27 & 1,51 & 2,75 & 2,13 & 1,0 & 1,3 & 54,10 \\
\hline $\mathrm{C} 2$ & $140-160$ & 50 & 882 & 48 & 20 & 3,63 & 4,9 & 8,32 & 2,50 & 35,52 & 23 & 23 & 1,35 & 1,19 & 1,28 & 3,02 & 2,09 & 0,9 & 1,4 & 57,37 \\
\hline C3 & $160-175$ & 116 & 792 & 72 & 20 & 3,33 & 4,7 & 10,22 & 2,50 & 38,02 & 27 & 20 & 1,70 & 1,79 & 1,55 & 3,88 & 2,18 & 0,9 & 1,8 & 65,28 \\
\hline $\mathrm{C} 4$ & $175-210$ & 60 & 902 & 18 & 20 & .. & 4,8 & 9,29 & 0,80 & 22,49 & 41 & 8 & 0,38 & 0,36 & 0,29 & 1,68 & 0,83 & 0,8 & 2,0 & 30,00 \\
\hline
\end{tabular}

$\begin{array}{llllllllllllllllllllll}\text { A1 } & 0-13 & 102 & 780 & 98 & 20 & 20,61 & 3,8 & 7,11 & 36,60 & 90,71 & 8 & 84 & 1,69 & 1,18 & 1,28 & 0,71 & 0,74 & 0,8 & 1,0 & 3,57\end{array}$

$\begin{array}{lllllllllllllllllllll}\mathrm{A} 2 & 13-28 & 90 & 808 & 82 & 20 & 19,68 & 4,2 & 3,72 & 26,00 & 76,72 & 5 & 87 & 2,24 & 1,67 & 2,15 & 1,90 & 2,37 & 1,0 & 0,8 & 12,04\end{array}$

$\begin{array}{llllllllllllllllllllll}\mathrm{AE} & 28-63 & 86 & 850 & 44 & 20 & 9,37 & 4,7 & 2,74 & 7,60 & 33,34 & 8 & 74 & 1,06 & 1,72 & 1,85 & 2,51 & 2,40 & 1,7 & 1,0 & 25,61\end{array}$

$\begin{array}{lrlllllllllllllllllll}\mathrm{E} & 35-82 & 108 & 866 & 6 & 20 & 2,19 & 5,4 & 3,45 & 0,10 & 5,45 & 63 & 3 & 0,25 & 0,11 & 0,15 & 0,20 & 0,24 & 0,6 & 0,8 & 10,98\end{array}$

$\begin{array}{lllllllllllllllllll}\mathrm{EB} & 60-84 & 98 & 85 & 24 & 20 & 4,06 & 4,9 & 2,43 & 2,10 & 12,43 & 20 & 46 & 1,39 & 0,92 & 1,16 & 0,00 & 0,00 & 0,8\end{array}$

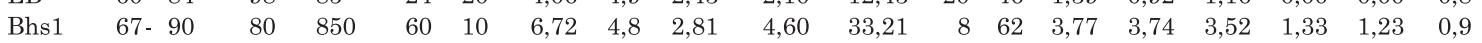

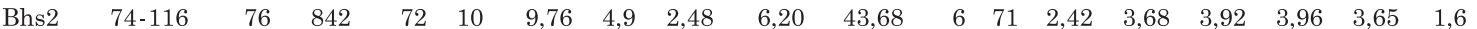

$\begin{array}{llllllllllllllllllll}\text { Bhs3 } & 116-140 & 74 & 842 & 44 & 40 & 9,06 & 5,0 & 1,58 & 5,20 & 49,38 & 3 & 77 & 1,82 & 3,06 & 3,92 & 4,61 & 5,33 & 2,2\end{array}$

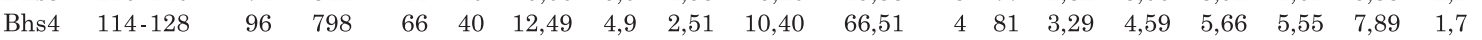

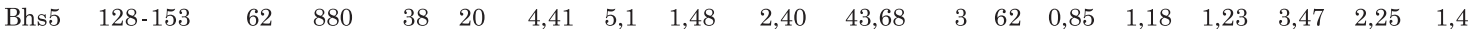

$\begin{array}{llllllllllllllllllll}\text { Bhs6 } & 126-152 & 68 & 856 & 56 & 20 & 6,10 & 5,2 & 2,79 & 4,40 & 47,99 & 6 & 61 & 1,32 & 1,57 & 1,53 & 4,44 & 2,88 & 1,2\end{array}$

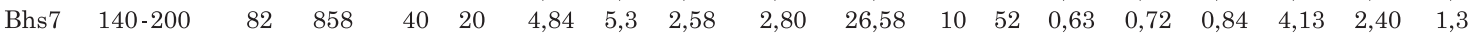

C2 $180-200$

$84 \quad 890$

$\begin{array}{rrrrrrrrrrrrrrr}40 & 20 & 4,84 & 5,3 & 2,58 & 2,80 & 26,58 & 10 & 52 & 0,63 & 0,72 & 0,84 & 4,13 & 2,40 & 1,3 \\ 16 & 10 & 1,25 & 5,6 & 5,97 & 0,40 & 9,97 & 60 & 6 & 0,36 & 0,52 & 0,61 & 1,31 & 0,90 & 1,7\end{array}$

$1,1 \quad 18,32$

$1,1 \quad 40,24$

$0,9 \quad 58,79$

$0,7 \quad 63,15$

$1,5 \quad 55,41$

$1,5 \quad 47,29$

$1,7 \quad 49,57$

Bertioga - Perfil P3: Espodossolo Ferri-Humilúvico órtico dúrico, A moderado, textura arenosa, bem drenado

\begin{tabular}{|c|c|c|c|c|c|c|c|c|c|c|c|c|c|c|c|c|c|c|c|c|}
\hline $\mathrm{A} 1$ & $0-6$ & 24 & 846 & 90 & 40 & 36,52 & 4,2 & 27,84 & 3,90 & 129,04 & 22 & 12 & 0,22 & 0,13 & 0,06 & 0,00 & 0,00 & 0,3 &.. & .. \\
\hline $\mathrm{A} 2$ & 6- 13 & 48 & 908 & 24 & 20 & 13,33 & 4,4 & 10,40 & 7,50 & 41,20 & 25 & 42 & 0,12 & 0,00 & 0,00 & 0,00 & 0,00 & .. & .. & .. \\
\hline EA & $13 \cdot 25$ & 28 & 942 & 10 & 20 & 2,12 & 4,6 & 9,53 & 1,60 & 16,73 & 57 & 14 & 0,00 & 0,00 & 0,00 & 0,00 & 0,00 & .. &.. & $\cdot$ \\
\hline 1 & $25-71$ & 16 & 956 & 8 & 20 & 0,61 & 5,7 & 10,34 & 0,10 & 10,54 & 98 & 1 & 0,00 & 0,00 & 0,00 & 0,00 & 0,00 & .. &.. &. \\
\hline 2 & $106-180$ & 92 & 882 & 6 & 20 & 0,30 & 5,5 & 9,98 & 0,20 & 9,98 & 100 & 2 & 0,00 & 0,00 & 0,00 & 0,00 & 0,00 & .. &.. & \\
\hline $\mathrm{EB}$ & $94-113$ & 74 & 900 & 6 & 20 & 1,21 & 5,3 & 9,93 & 1,00 & 17,73 & 56 & 9 & 0,00 & 0,00 & 0,00 & 0,00 & 0,00 & .. &.. & \\
\hline $3 \mathrm{E} 1$ & $71-82$ & 56 & 726 & 138 & 80 & 8,78 & 5,2 & 13,48 & 9,80 & 68,48 & 20 & 42 & 0,07 & 0,00 & 0,00 & 0,47 & 0,47 & .. & 1,0 & 5,29 \\
\hline $\mathrm{E} 2$ & $73-91$ & 80 & 718 & 142 & 60 & 18,17 & 4,6 & 10,63 & 23,20 & 129,83 & 8 & 69 & 0,00 & 0,00 & 0,00 & 1,49 & 1,46 & .. & 1,0 & 8,03 \\
\hline h1 & $82-119$ & 98 & 840 & 42 & 20 & 19,69 & 4,3 & 10,13 & 25,30 & 134,33 & 8 & 71 & 0,00 & 0,00 & 0,00 & 1,45 & 1,49 & .. & 1,0 & 7,54 \\
\hline 3h2 & $107-125$ & 84 & 870 & 26 & 20 & 11,51 & 4,5 & 10,03 & 17,30 & 92,03 & 11 & 63 & 0,00 & 0,00 & 0,00 & 0,89 & 0,86 & .. & 1,0 & 7,43 \\
\hline h3 & $135-170$ & .. & .. & .. & .. & 11,81 & 4,5 & 9,99 & 18,90 & 85,79 & 12 & 65 & 0,00 & 0,00 & 0,00 & 0,73 & 0,81 & .. & 0,9 & 6,8 \\
\hline $\mathrm{hm} 1$ & $89-125$ & 98 & 806 & 76 & 20 & 36,52 & 4,2 & 9,87 & 39,50 & 241,87 & 4 & 80 & 0,00 & 0,00 & 0,00 & 3,11 & 3,27 & .. & 0,9 & 8,9 \\
\hline Bhm2 & $120-142$ & 92 & 778 & 70 & 60 & 22,72 & 4,7 & 8,80 & 18,80 & 166,80 & 5 & 68 & 0,00 & 0,00 & 0,00 & 4,44 & 4,83 & .. & 0,9 & 21,26 \\
\hline s 1 & $107-125$ & 108 & 864 & 8 & 20 & 5,45 & 4,8 & 9,93 & 7,00 & 56,93 & 17 & 41 & 0,00 & 0,00 & 0,00 & 0,87 & 0,86 & .. & 1,0 & 15,68 \\
\hline s2 & $125-180$ & 86 & 876 & 18 & 20 & 4,24 & 5,2 & 8,17 & 3,70 & 55,1 & 15 & 31 & 0,16 & 0,12 & 0,10 & 3,21 & 1,91 & 0,6 & 1,7 & 44,93 \\
\hline Bsm1 & $122-144$ & 92 & 816 & 72 & 20 & 19,99 & 4,6 & 10,03 & 23,60 & 148,63 & 7 & 70 & 0,09 & 0,06 & 0,05 & 2,64 & 2,87 & 0,5 & 0,9 & 14,33 \\
\hline Bsm2 & $153-180$ & 72 & 868 & 40 & 20 & 8,18 & 5,2 & 10,17 & 4,30 & 81,57 & 12 & 30 & 0,09 & 0,00 & 0,00 & 6,17 & 3,20 & .. & 1,9 & 39,07 \\
\hline Bsm3 & $132-170$ & 106 & 834 & 40 & 20 & 11,02 & 4,7 & 11,88 & 7,90 & 115,28 & 10 & 40 & 0,00 & 0,00 & 0,00 & 4,05 & 2,82 & .. & 1,4 & 25,5 \\
\hline sm4 & $157-180$ & 78 & 860 & 42 & 20 & 15,75 & 4,8 & 9,35 & 14,40 & 122,95 & 8 & 61 & 0,19 & 0,19 & 0,14 & 4,45 & 3,20 & 0,7 & 1,4 & 20,2 \\
\hline
\end{tabular}

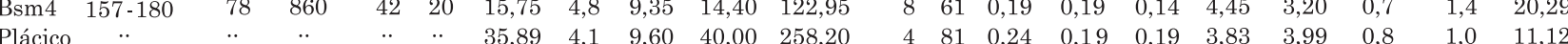

Bertioga - Perfil P7: Espodossolo Ferri-Humilúvico hidromórfico espessarênico, A moderado, textura arenosa, mal drenado

\begin{tabular}{|c|c|c|c|c|c|c|c|c|c|c|c|c|c|c|c|c|c|c|c|c|}
\hline $\mathrm{A} 1$ & $0 . \quad 8$ & 40 & 822 & 118 & 20 & 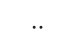 & 4,3 & 28,22 & 26,20 & 211,62 & 13 & 48 & 0,53 & 0,20 & 0,08 & 0,32 & 0,13 & 0,2 & 2,4 & \\
\hline A2 & 8- 13 & 30 & 862 & 88 & 20 & 35,26 & 4,2 & 14,84 & 42,90 & 77,04 & 19 & 74 & 0,25 & 0,18 & 0,15 & 0,19 & 0,09 & 0,6 & 2,1 & 0,26 \\
\hline $\mathrm{AE} 1$ & 13- 19 & 30 & 896 & 54 & 20 & 10,39 & 4,4 & 7,91 & 9,40 & 51,91 & 15 & 54 & 0,10 & 0,00 & 0,00 & 0,00 & 0,00 & .. & .. & \\
\hline $\mathrm{E} 2$ & 19. 26 & 18 & 950 & 22 & 10 & 8,18 & 4,4 & 1,51 & 7,50 & 37,91 & 4 & 83 & 0,00 & 0,00 & 0,00 & 0,27 & 0,18 & & 1,5 & 2,20 \\
\hline h1 & $26 \cdot 37$ & 14 & 938 & 38 & 10 & 11,65 & 4,2 & 6,82 & 16,70 & 66,82 & 10 & 71 & 0,00 & 0,00 & 0,00 & 0,52 & 0,68 & & 0,8 & 5,8 \\
\hline $3 \mathrm{~h} 2$ & 37- 59 & 26 & 912 & 52 & 10 & 10,39 & 3,7 & 1,30 & 25,10 & 86,50 & 2 & 95 & 0,00 & 0,00 & 0,00 & 0,88 & 0,96 & .. & 0,9 & 9,2 \\
\hline $3 \mathrm{~s}$ & 59- 74 & 18 & 928 & 44 & 10 & 5,67 & 3,1 & 10,06 & 65,10 & 136,46 & 7 & 87 & 1,78 & 1,37 & 1,15 & 0,74 & 0,69 & 0,6 & 1,1 & 2,18 \\
\hline $\mathrm{Cg}$ & 74- 84 & 14 & 940 & 36 & 10 & 4,41 & 3,5 & 2,07 & 49,70 & 76,47 & 3 & 96 & 0,71 & 0,55 & 0,59 & 0,56 & 0,54 & 0,8 & 1,0 & 2,2 \\
\hline$g$ & $84-100$ & 18 & 934 & 38 & 10 & 1,89 & 3,1 & 0,92 & 46,00 & 62,32 & 1 & 98 & 2,01 & 1,67 & 1,81 & 0,41 & 0,30 & 0,9 & 1,4 & 5,88 \\
\hline \multicolumn{21}{|c|}{ Bertioga - Perfil P10: Espodossolo Humilúvico hidromórfico espessarênico, A moderado, textura arenosa, mal drenado } \\
\hline A & $0-7$ & 40 & 684 & 216 & 60 & 67,37 & 3,9 & 19,39 & 26,10 & 178,59 & 11 & 57 & 0,50 & 0,36 & 0,25 & 0,32 & 0,20 & 0,5 & 1,6 & 0,29 \\
\hline $\mathrm{AE}$ & 7- 11 & 34 & 894 & 52 & 20 & 20,46 & 4,1 & 6,92 & 23,80 & 95,92 & 7 & 77 & 0,08 & 0,00 & 0,00 & 0,26 & 0,00 & .. & .. & \\
\hline $\mathrm{EA}$ & $11-30$ & 8 & 958 & 24 & 10 & 8,81 & 4,2 & 2,83 & 6,50 & 34,43 & 8 & 70 & 0,00 & 0,00 & 0,00 & 0,00 & 0,00 & & .. & \\
\hline E & 18- 48 & 6 & 980 & 4 & 10 & 1,26 & 4,9 & 3,89 & 14,40 & 6,29 & 62 & 79 & 0,00 & 0,00 & 0,00 & 0,00 & 0,00 & .. & 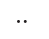 & 10,32 \\
\hline $\mathrm{EB}$ & $35-74$ & 12 & 970 & 8 & 10 & 1,57 & 4,7 & 5,6 & 16,40 & 17,07 & 33 & 74 & 0,00 & 0,00 & 0,00 & 0,00 & 0,00 & .. &.. & \\
\hline $\mathrm{BE}$ & $60-83$ & 10 & 978 & 2 & 10 & 4,09 & 4,5 & 1,39 & 7,50 & 30,59 & 5 & 84 & 0,14 & 0,00 & 0,00 & 0,26 & 0,13 & .. & 2,0 & 3,1 \\
\hline Bh1 & $83-103$ & 28 & 920 & 42 & 10 & 15,11 & 3,9 & 1,55 & 43,20 & 121,95 & 1 & 97 & 0,00 & 0,00 & 0,00 & 0,21 & 0,66 &.. & 0,3 & 4,37 \\
\hline $\mathrm{Bh} 2$ & $90-117$ & 28 & 934 & 28 & 10 & 19,52 & 4,1 & 0,67 & 45,00 & 173,67 & 0 & 99 & 0,12 & 0,00 & 0,00 & 0,78 & 1,23 & .. & 0,6 & 6,30 \\
\hline Bhm & $117-150$ & 22 & 930 & 28 & 20 & 18,57 & 4,1 & 0,57 & 46,50 & 119,77 & 0 & 99 & 0,00 & 0,00 & 0,00 & 0,84 & 1,38 & .. & 0,6 & 7,4 \\
\hline
\end{tabular}

Continua... 


\section{Quadro 1. Continuação}

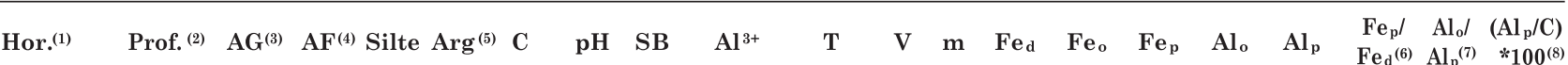

\begin{tabular}{|c|c|c|c|c|c|c|c|c|c|c|c|c|c|c|c|c|c|c|c|c|}
\hline \\
\hline \multicolumn{21}{|c|}{ Bertioga - Perfil P11: Espodossolo Humilúvico hidromórfico espessarênico, A moderado, textura arenosa, mal drenado } \\
\hline A & $0-14$ & 10 & 978 & 2 & 10 & 17,31 & 4,4 & 3,24 & 8,60 & 126,74 & 3 & 73 & 0,16 & 0,00 & 0,00 & 0,00 & 0,00 & .. & .. & .. \\
\hline EA & $14-35$ & 18 & 892 & 70 & 20 & 2,20 & 4,3 & 0,00 & 1,90 & 1,92 & 9 & 92 & 0,00 & 0,00 & 0,00 & 0,00 & 0,00 & .. & .. & .. \\
\hline E1 & $29-71$ & 2 & 978 & 10 & 10 & 0,63 & 4,8 & 0,00 & 4,40 & 0,67 & 10 & 98 & 0,00 & 0,00 & 0,00 & 0,00 & 0,00 & .. & .. & .. \\
\hline $\mathrm{E} 2$ & $53-100$ & 6 & 982 & 2 & 10 & 0,00 & 5,3 & 0,00 & 4,40 & 0,77 & 22 & 96 & 0,00 & 0,00 & 0,0 & 0,00 & 0,00 & .. & .. & .. \\
\hline E3 & $84-112$ & 4 & 984 & 2 & 10 & 0,00 & 4,7 & 0,00 & 0,50 & 0,72 & 17 & 81 & 0,00 & 0,00 & 0,00 & 0,00 & 0,00 &.. & .. & .. \\
\hline $\mathrm{EB}$ & $112-122$ & 2 & 986 & 2 & 10 & 1,57 & 4,6 & 0,32 & 8,90 & 15,32 & 2 & 97 & 0,00 & 0,00 & 0,00 & 0,00 & 0,06 &.. & .. & 3,81 \\
\hline Bh1 & $122-140$ & 2 & 984 & 4 & 10 & 5,04 & 4,7 & 0,77 & 10,60 & 43,57 & 2 & 93 & 0,00 & 0,00 & 0,00 & 0,25 & 0,41 &.. & 0,6 & 8,04 \\
\hline Bh2 & $140-160$ & 6 & 970 & 14 & 10 & 5,35 & 4,5 & 0,42 & 16,00 & 103,42 & 0 & 97 & 0,00 & 0,00 & 0,00 & 0,85 & 0,92 &.. & 0,9 & 17,10 \\
\hline \multicolumn{21}{|c|}{ Bertioga - Perfil P12: Neossolo Quartzarênico hidromórfico típico, A moderado, muito mal drenado } \\
\hline A1 & $0-8$ & 12 & 952 & 26 & 10 & 30,30 & 3,9 & 15,65 & 18,60 & 108,05 & 14 & 54 & 2,47 & 1,19 & 1,45 & 0,18 & 0,23 & 0,6 & 0,8 & 0,74 \\
\hline $\mathrm{A} 2$ & 8- 24 & 40 & 836 & 114 & 10 & 34,20 & 3,7 & 9,87 & 20,00 & 79,87 & 12 & 67 & 2,96 & 1,98 & 2,12 & 0,32 & 0,32 & 0,7 & 1,0 & 0,92 \\
\hline $\mathrm{AE}$ & 24- 30 & 26 & 862 & 102 & 10 & 9,21 & 3,9 & 7,91 & 12,00 & 23,71 & 33 & 60 & 2,90 & 2,21 & 2,41 & 0,33 & 0,39 & 0,8 & 0,8 & 4,23 \\
\hline $\mathrm{C}$ & $30-48$ & 10 & 932 & 48 & 10 & 4,22 & 4,4 & 6,82 & 17,30 & 36,02 & 19 & 72 & 8,10 & 3,67 & 4,47 & 0,92 & 0,89 & 0,6 & 1,0 & 20,99 \\
\hline $\mathrm{Cg} 1$ & $48-83$ & 16 & 926 & 48 & 10 & 1,72 & 4,8 & 5,91 & 18,70 & 23,91 & 25 & 76 & 6,10 & 1,66 & 1,83 & 0,66 & 0,56 & 0,3 & 1,2 & 32,31 \\
\hline Cg2 & $83-110$ & 24 & 952 & 14 & 10 & 0,78 & 5,6 & 5,75 & 5,10 & 8,75 & 66 & 47 & 3,60 & 0,27 & 0,30 & 0,60 & 0,30 & 0,1 & 2,0 & 38,42 \\
\hline
\end{tabular}

Bertioga - Perfil P13: Neossolo Quartzarênico hidromórfico típico, A moderado, mal drenado

\begin{tabular}{|c|c|c|c|c|c|c|c|c|c|c|c|c|c|c|c|c|c|c|c|c|}
\hline $\mathrm{A} 1$ & $0-7$ & 46 & 838 & 76 & 40 & 21,41 & 4,4 & 36,12 & 26,20 & 97,32 & 37 & 42 & 6,50 & 1,40 & 0,68 & 0,40 & 0,20 & 0,1 & 2,1 & 0,91 \\
\hline $\mathrm{A} 2$ & 7- 15 & 42 & 860 & 78 & 20 & 11,96 & 4,5 & 18,83 & 13,30 & 76,83 & 25 & 41 & 10,60 & 1,70 & 1,03 & 0,49 & 0,30 & 0,1 & 1,6 & 2,51 \\
\hline $\mathrm{C} 1$ & $15 \quad 63$ & 8 & 78 & 4 & 10 & 0,94 & 5,9 & 29,57 & 7,00 & 38,77 & 76 & 19 & 7,50 & 0,84 & 0,22 & 0,33 & 00 &.. & .. & \\
\hline $\mathrm{C} 2$ & $57-82$ & 6 & 82 & 2 & 10 & 0,31 & 6,1 & 1,81 & 6,80 & 36,81 & 86 & 18 & 7,10 &, 79 & 0,00 & 0,32 & ,00 &.. & .. & \\
\hline C3 & $73-94$ & 8 & 80 & 2 & 10 & 0,00 & 6,3 & 9,46 & 0,40 & 33,46 & 88 & 1 & 9,30 &, 84 & 0,00 & 0,39 & 00 &.. & 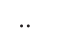 & \\
\hline $\mathrm{C} 4$ & $94-100$ & 6 & 82 & 2 & 0 & 0,00 & 6,5 & 5,66 & 5,40 & 36,66 & 97 & 13 & 6,90 & ,77 & 0,00 & 35 & 00 &.. & & \\
\hline $\mathrm{Cg}$ & $3-82$ & 10 & 978 & 2 & 10 & 0,00 & 6,0 & 22,86 & 0,90 & 27,36 & 84 & 4 & 8,70 & 1,14 & 0,14 & 0,36 & 0,00 &.. &.. & \\
\hline \multicolumn{21}{|c|}{ Bertioga - Perfil P14: Espodossolo Ferri-Humilúvico órtico espessarênico, A moderado, textura arenosa, moderadamente drenado } \\
\hline A1 & $0-12$ & 66 & 860 & 54 & 20 & 9,68 & 4,4 & 14,70 & 7,00 & 33,30 & 44 & 32 & 0,41 & 0,00 & 0,00 & 0,00 & 0,00 & .. & .. & \\
\hline 2 & $12-22$ & 40 & 30 & 20 & 10 & 8,59 & 4,2 & 8,70 & 5,80 & 22,30 & 39 & 40 & 0,18 & ,00 & 0,00 & 0,00 & 0,00 &.. &.. & \\
\hline $\mathrm{AE}$ & $22-30$ & 36 & 940 & 14 & 10 & 3,90 & 4,2 & 6,64 & 2,60 & 12,64 & 3 & 28 & 0,16 & 00 & 0,00 & 0,00 & 0,00 & .. & . & \\
\hline $\mathrm{E}$ & $30-59$ & 28 & 56 & 6 & 10 & 2,19 & 4,4 & 5,65 & 2,10 & 10,05 & 6 & 27 & 0,19 & 00 &, 00 & 00 &, 00 &.. & 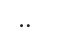 & \\
\hline $\mathrm{h}$ & $43-71$ & 26 & 30 & 24 & 20 & 6,09 & 4,4 & 7,52 & 13,70 & 39,72 & 19 & 65 & 1,29 &, 57 & 1,85 & 0,43 & 0,44 & 1,4 & 1,0 & 7,22 \\
\hline Bs1 & $56-81$ & 72 & 06 & 12 & 10 & 3,28 & 4,9 & 7,63 & 8,20 & & 43 & 52 & 1,11 & 84 & 0,45 & 0,45 & 0,45 & 0,4 & 1,0 & 13,72 \\
\hline Bs2 & $65-110$ & 100 & 88 & 2 & 10 & 2,19 & 5,2 & 6,84 & 5,00 & 4 & 38 & 42 & 1,06 & 1,00 & 0,39 & 0,49 & 0,39 & 0,4 & 1,3 & 7,84 \\
\hline $\mathrm{C} 1$ & $84-124$ & 10 & 64 & 16 & 10 & 1,25 & 5,5 & 5,87 & 3,00 & 11,07 & 53 & 34 & 0,55 & 33 & 0,17 & 29 & 0,17 & 0,3 & 1,7 & 3,61 \\
\hline $\mathrm{C} 2$ & $5-135$ & 60 & 928 & 2 & 10 & 0,62 & 5,6 & 4,92 & 2,50 & 8,92 & 55 & 34 & 0,47 & 0,19 & 0,15 & 0,26 & 0,15 & 0,3 & 1,7 & 4,01 \\
\hline \multicolumn{21}{|c|}{ Bertioga - Perfil P15: Espodossolo Humilúvico hiperespesso espessarênico, A moderado, excessivamente drenado } \\
\hline A & $0-20$ & 20 & 812 & 148 & 20 & 35,45 & 3,7 & 22,82 & 10,50 & 81,22 & 28 & 32 & 0,13 & 0,00 & 0,00 & 0,00 & 0,07 &.. &.. & 0,19 \\
\hline EA & $20-40$ & 2 & 974 & 14 & 10 & 3,59 & 4,1 & 5,12 & 2,30 & 9,52 & 54 & 31 & 0,07 & 0,00 & 0,00 & 0 & 0,00 & 0,1 & 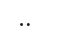 & \\
\hline 1 & $40-60$ & 2 & 980 & 8 & 10 & 0,94 & 4,5 & 4,65 & 0,60 & 4,65 & 100 & 11 & 0,00 & 00 & 0,00 & 0 & 0,00 &.. &.. & - \\
\hline E2 & $60-160$ & 2 & 82 & 6 & 10 & 0,47 & 5,2 & 3,27 & 0,00 & 3,27 & 100 & 3 & 0,00 & 0,00 & 0,00 & 0,00 & 0,00 & .. & .. & \\
\hline E3 & $60-215$ & 6 & 80 & 4 & 10 & 0,00 & 5,5 & 4,70 & 0,00 & 4,70 & 100 & 2 & 0,00 & 0,00 & 0,00 & 0,00 & 0,00 &.. & 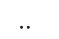 & \\
\hline $\mathrm{EB}$ & $5-305$ & 10 & 74 & 6 & 10 & 1,4 & 5,1 & 6,44 & 2,70 & 44 & 42 & 30 & 0,00 & & 0,00 & & &.. & .. & \\
\hline h1 & $5-330$ & 28 & 42 & 20 & 10 & 9,37 & 4,4 & 5,40 & 27,00 & 60 & 9 & 83 & 0,00 & 0,00 & 0,00 & 43 & 0,65 &.. & 0,7 & 6,94 \\
\hline $\mathrm{hm}$ & -360 & 34 & 26 & 20 & 20 & 13,43 & 4,3 & 12,12 & 29,90 & & 12 & 71 & 0,00 & 0,00 & 0,00 & 0,89 & 1,09 & .. & 0,8 & 8,12 \\
\hline $\mathrm{Bh} 2$ & $0-400$ & 42 & 922 & 16 & 20 & 10,15 & 4,3 & 11,43 & 24,30 & 74,43 & 15 & 68 & 0,00 & 0,00 & 0,00 & 0,69 & 0,93 &.. & 0,7 & \\
\hline \multicolumn{21}{|c|}{ Bertioga- Perfil P16: Espodossolo Ferri-Humilúvico órtico espessarênico, A moderado, textura arenosa, fortemente drenado } \\
\hline A & $0-20$ & 44 & 840 & 50 & 20 &, 36 & 3,9 & ,29 & 15,50 & 123,29 & 12 & 50 & 0,43 & 0,27 & 0,26 & 0,3 & & 0,6 & 1 & 0,72 \\
\hline EA & $20-32$ & 12 & 954 & 14 & 20 & 6,72 & 4,1 & 7,27 & 6,90 & 21,27 & 34 & 49 & 0,21 & & 0,09 & & 0,14 & 0,4 & 2,2 & 2,08 \\
\hline E1 & $32-77$ & 6 & 982 & 2 & 10 & 1,56 & 4,7 & 3,54 & 0,50 & 3,54 & 100 & 12 & 0,00 & 0,00 & 0,00 & 0,27 & 0,00 &.. &.. & .. \\
\hline $\mathrm{E} 2$ & $77-97$ & 2 & 986 & 2 & 10 & 1,25 & 5,2 & 5,28 & 0,80 & 8,88 & 59 & 13 & 0,00 & 0,00 & 0,00 & 0,00 & 0,00 &.. & .. & \\
\hline Bh1 & $90-121$ & 2 & 964 & 14 & 20 & & 4,3 & 6,34 & 15,10 & & 20 & 70 & 0,00 & 0,00 & 0,00 & & &.. & 1,0 & 9,93 \\
\hline $\mathrm{Bh} 2$ & $121-170$ & 6 & 972 & 2 & 20 & 2,81 & 5,0 & 5,34 & 6,20 & 4 & 32 & 54 & 0,00 & 0,00 & 0,00 & 31 & 0,15 &.. & 2,1 & 5,18 \\
\hline Bh3 & $4-193$ & 2 & 974 & 4 & 20 & 3,75 & 4,9 & 7,35 & 10,50 & & 24 & 59 & 0,00 & 0,00 & 0,00 & 0,45 & 0,36 & .. & 1,3 & 9,60 \\
\hline $\mathrm{Bh} 4$ & -253 & 8 & & 6 & 20 & & 4,9 & & 13,50 & & 14 & 66 & 0,00 & 0,00 & 0,00 & & &.. & 0,8 & 0,91 \\
\hline Bs & $3-300$ & 20 & 948 & 12 & 20 & 3,90 & 4,7 & 12,83 & 5,90 & 40,83 & 31 & 32 & 0,00 & 0,00 & 0,00 & 0,42 & 0,50 &.. & 0,8 & 68 \\
\hline \multicolumn{21}{|c|}{ Ilha Comprida - Perfil P17: Espodossolo Ferri-Humilúvico órtico espessarênico, A moderado, textura arenosa, moderadamente drenado } \\
\hline A & $0-30$ & & & 96 & 20 & & 4,0 & & 11,25 & & 11 & 46 & & & & & 0,00 & .. & .. & \\
\hline EA & $30-52$ & 40 & 938 & 2 & 20 & & 4,2 & & & & 22 & 32 & & & & & & "* & .. & \\
\hline E1 & $52-88$ & 24 & 964 & 2 & 10 & 1,54 & 4,6 & 6,34 & 0,00 & 65,94 & 10 & 2 & 0,00 & 0,00 & 0,00 & 0,00 & 0,00 &.. &.. & 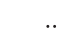 \\
\hline E2 & $88-115$ & 52 & 936 & 2 & 10 & 1,39 & 4,8 & 5,18 & 0,00 & 5,98 & 87 & 1 & 0,00 & 0,00 & 0,00 & 0,00 & 0,00 & .. &.. & 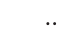 \\
\hline $\mathrm{BE}$ & $15-130$ & 48 & 940 & 2 & 10 & 4,94 & 4,6 & 5,54 & 3,45 & & 31 & 38 & 0,00 & 0,00 & 0,00 & 0,14 & 0,12 &.. & 1,2 & 2,46 \\
\hline $\mathrm{Bh}$ & $130-243$ & 108 & 866 & 16 & 10 & 8,95 & 4,6 & 7,54 & 8,65 & 8,94 & 84 & 53 & 0,00 & 0,00 & 0,00 & 0,60 & 0,53 & $\cdot$ & 1,1 & 5,91 \\
\hline Bs & $243-485$ & 148 & 840 & 2 & 10 & 4,48 & 5,0 & 10,24 & 2,65 & 30,24 & 34 & 21 & 0,00 & 0,00 & 0,00 & 0,51 & 0,36 &.. & 1,4 & 8,01 \\
\hline $\mathrm{C}$ & $485-500$ & 306 & 680 & 4 & 10 & 3,24 & 5,5 & 15,76 & 1,05 & 27,96 & 56 & 6 & 0,10 & 0,00 & 0,00 & 0,35 & 0,22 &.. & 1,6 & 6,85 \\
\hline
\end{tabular}


Quadro 1. Continuação

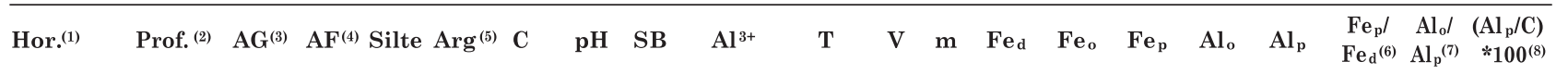

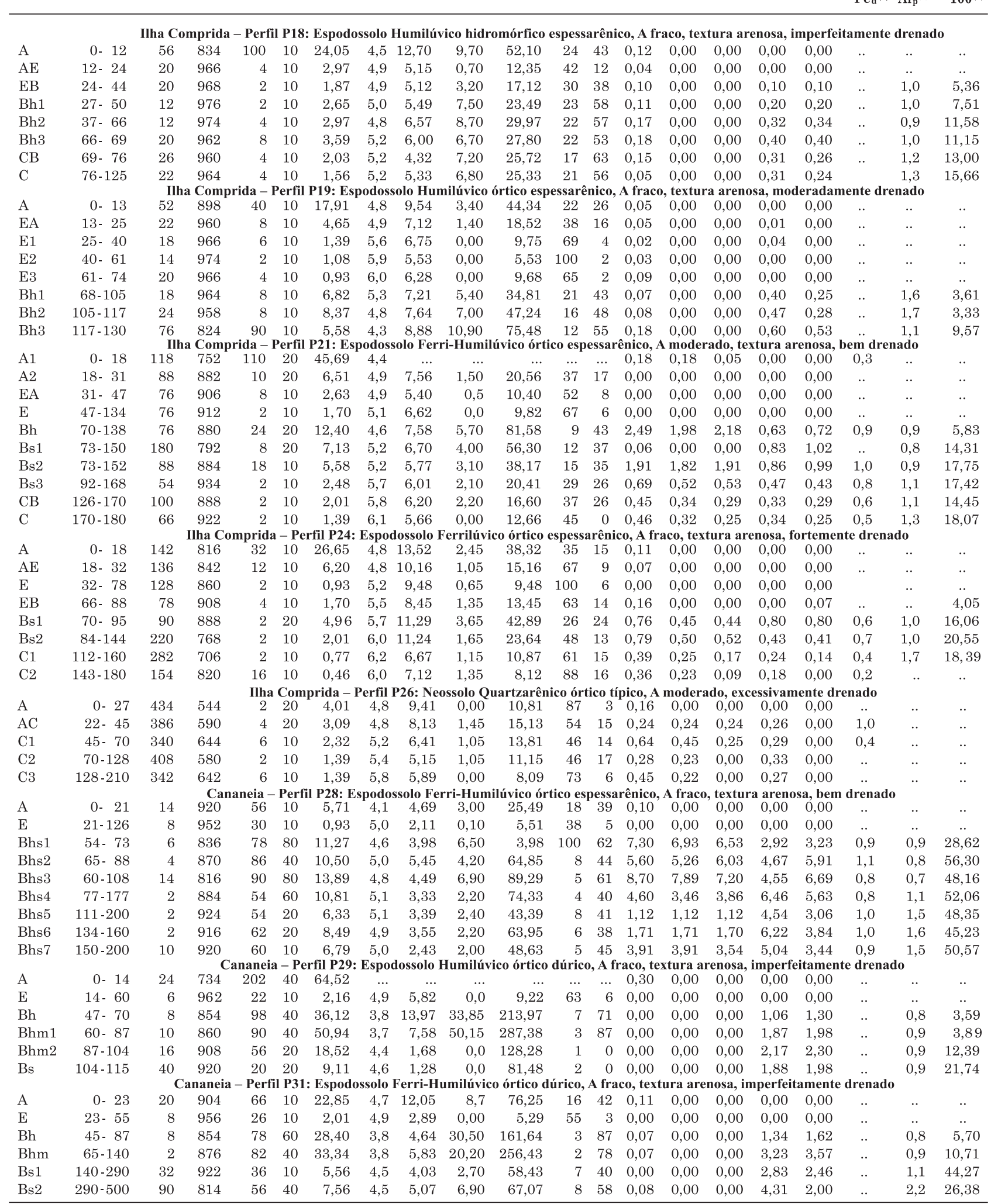

${ }^{(1)}$ Horizonte. ${ }^{(2)}$ Profundidade. ${ }^{(3)}$ AG: grossa $(0,25$ a $2 \mathrm{~mm}) .{ }^{(4)} \mathrm{AF}$ : fina $(0,05-0,25 \mathrm{~mm}) .{ }^{(5)}$ Arg: argila $(<0,002 \mathrm{~mm}) .{ }^{(6)} \mathrm{Fe}_{\mathrm{p}} / \mathrm{Fe}_{\mathrm{d}}: \mathrm{relação} \mathrm{entre}$ os teores de $\mathrm{Fe}$ extraídos com pirofosfato $\left(\mathrm{Fe}_{\mathrm{p}}\right)$ e ditionito-citrato $\left(\mathrm{Fe}_{\mathrm{d}}\right) \cdot{ }^{(7)} \mathrm{Al}_{\mathrm{o}} / \mathrm{Al}_{\mathrm{p}}$ : relação entre os teores de $\mathrm{Al}$ extraídos com oxalato $\left(\mathrm{Al}_{\mathrm{o}}\right)$ e pirofosfato $\left(\mathrm{Al}_{\mathrm{p}}\right) \cdot{ }^{(8)}\left(\mathrm{Al}_{\mathrm{p}} / \mathrm{C}\right)^{*}$ 100: relação entre o $\mathrm{Al}$ extraído por pirofosfato $\left(\mathrm{Al}_{\mathrm{p}}\right)$ e o C. Medida da percentagem do grau de saturação por Al na matéria orgânica do solo. Sinais convencionais utilizados: ... Dado numérico não disponível; .. Não se aplica dado numérico. 


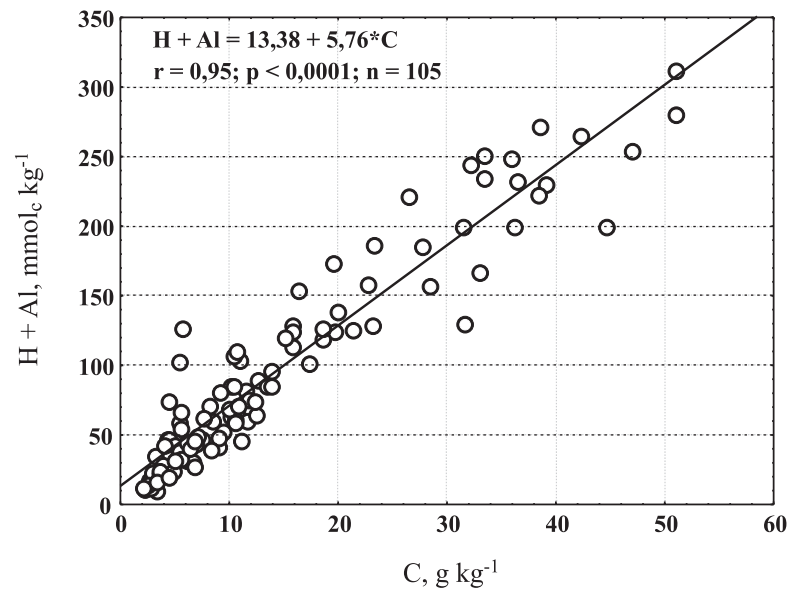

Figura 4. Relação entre o C e a acidez potencial $(\mathrm{H}+\mathrm{Al})$ para os horizontes espódicos de todos os perfis estudados. A boa correlação entre as variáveis evidencia que o C é o principal responsável pelo desenvolvimento da acidez nos solos sob vegetação de restinga.

A figura 5 mostra a correlação entre $\mathrm{Al}_{\mathrm{p}} / \mathrm{C}$ e as variáveis $\mathrm{pH}$ do solo (medido em água) e a relação $\mathrm{Al}_{\mathrm{o}} /$ $\mathrm{Al}_{\mathrm{p}}$. Observa-se que o aumento da saturação por $\mathrm{Al}$ no húmus é acompanhado tanto pela menor dispersão dos dados em torno do $\mathrm{pH} 5$, como pela maior concentração de amostras com valores de $\mathrm{Al}_{\mathrm{o}} / \mathrm{Al}_{\mathrm{p}}$ superiores a uma unidade. Também é evidente que acima de $20 \%$ de $\mathrm{Al} / \mathrm{C}$ há total dominância de horizontes B com subscrito "s" e horizontes C, todos bem drenados. Segundo Shoji \& Fujiwara (1984), a acidez do solo controla a formação de complexos de $\mathrm{Al}$ e Fe-húmus, de forma que, em valores de $\mathrm{pH}$ inferiores a 4,9, $\mathrm{Al}$ forma complexos estáveis com a matéria orgânica do solo (Shoji et al., 1982). Daí os valores acima de uma unidade da relação $\mathrm{Al}_{\mathrm{o}} / \mathrm{Al}_{\mathrm{p}}$ para muitos dos horizontes $\mathrm{Bs}$, Bhs, Bsm e $\mathrm{C}$ à medida que há aumento do $\mathrm{pH}$ para valores próximos ou acima de 5 (Figura 5), indicando que compostos inorgânicos amorfos estão presentes, uma vez que o extrator oxalato é mais específico tanto para formas orgânicas como inorgânicas de $\mathrm{Al}$ de baixa cristalinidade, enquanto o pirofosfato o é apenas para formas orgânicas do elemento (Childs et al., 1983). No entanto, os baixos valores médios de $\mathrm{pH}(4,5)$ dos horizontes espódicos aqui estudados (Quadro 1) sugerem que a química é mais favorável à interação Al-matéria orgânica, sobretudo para horizontes Bh e Bhm, praticamente destituídos de $\mathrm{Fe}$, com menores valores de $\mathrm{pH}$ e maiores conteúdos de $\mathrm{C}$ em relação aos horizontes $\mathrm{Bs}$, Bhs e Bsm.

A figura 5 também evidencia que muitos horizontes espódicos com subscrito "s" e alguns horizontes C detêm elevada percentagem de saturação por $\mathrm{Al}$ no húmus, acima de $20 \%$, estando entre as maiores observadas nos solos estudados. Acima desse valor há aumento significativo das formas mais estáveis da associação Al-húmus, representadas pela diferença $\mathrm{Al}_{\mathrm{p}}-\mathrm{Al}_{\mathrm{Cu}}$ (García-Rodeja et al., 2004); os horizontes espódicos com subscrito "s" mostram seus conteúdos de $\mathrm{Al}$ mais fortemente associados à matéria orgânica em relação aos demais horizontes estudados (Figura 6a). Por sua vez, as formas menos estáveis da associação, $\mathrm{Al}_{\mathrm{La}}-\mathrm{Al}_{\mathrm{K}}$ (García-Rodeja et al., 2004), tendem a reduzir seus teores juntamente com o aumento da relação $\mathrm{Al}_{\mathrm{p}} / \mathrm{C}$, o que se acentua em valores de $\mathrm{Al}_{\mathrm{p}} / \mathrm{C}$ acima de 20 (Figura 6b), corroborando a efetividade dos extratores e da interação entre eles na avaliação da estabilidade das formas de $\mathrm{Al}$ nos solos estudados, cuja gênese está predominantemente associada à queluviação de $\mathrm{Al}$ dos horizontes superiores e sua deposição naqueles mais profundos, como se verá adiante.

\section{Ferro}

Shoji \& Fujiwara (1984) mostraram que a formação de complexo de Fe-húmus ocorre intensivamente em valores de $\mathrm{pH}$ inferiores a 4, em que o íon $\mathrm{Fe}^{3+}$ é a espécie dominante do elemento. Como a maioria das amostras aqui estudadas, com conteúdos detectáveis de $\mathrm{Fe}$, apresentou valores médios de $\mathrm{pH}$ superiores a 4,4 (Quadro 1), é de se esperar que a contribuição do $\mathrm{Al}$ à acumulação de húmus seja muito superior que aquela do $\mathrm{Fe}$, fato constatado para a maioria dos solos aqui estudados, embora condições outras, como o

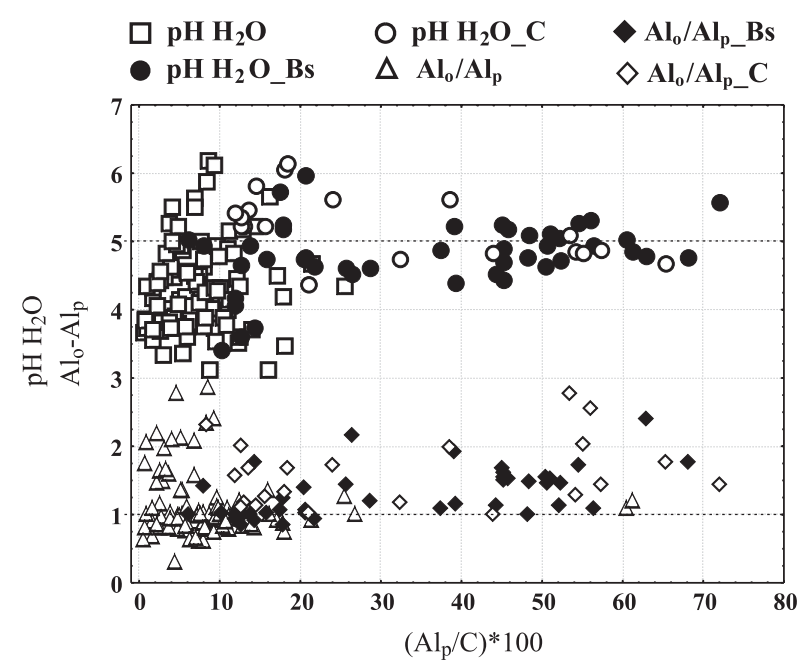

Figura 5. Relação entre a percentagem de saturação por $\mathrm{Al}$ no húmus $\left(\mathrm{Al}_{\mathrm{p}} / \mathrm{C}\right) * 100$ e as seguintes variáveis: $\mathrm{pH}$ extraído em água $\left(\mathrm{pH} \mathrm{H}_{2} \mathrm{O}\right)$ e a relação $\mathrm{Al}_{\mathrm{o}} / \mathrm{Al}_{\mathrm{p}} ; \mathrm{pH} \mathrm{H} \mathrm{H}_{2} \mathrm{O}$ e $\mathrm{Al}_{\mathrm{o}} / \mathrm{Al}_{\mathrm{p}}$ referem-se a todo o conjunto de horizontes e perfis estudados, excetuando-se horizontes Bs, Bhs, Bsm e C; pH $\mathrm{H}_{2} \mathrm{O} \_\mathrm{Bs}$ e $\mathrm{Al}_{\mathrm{o}} / \mathrm{Al}_{\mathrm{p}-} \mathrm{Bs}$, aos horizontes espódicos bem drenados dotados de subscrito " $\mathrm{s}$ " (Bs, Bhs e Bsm); $\mathrm{pH} \mathrm{H}_{2} \mathrm{O}_{-} \mathrm{C}$ e $\mathrm{Al}_{\mathrm{o}} / \mathrm{Al}_{\mathrm{p}-} \mathrm{C}$, aos horizontes $\mathrm{C}$. As linhas tracejadas indicam os valores de 1 e 5 para $\mathrm{Al}_{\mathrm{o}} / \mathrm{Al}_{\mathrm{p}}$ e $\mathrm{pH}$, respectivamente. 

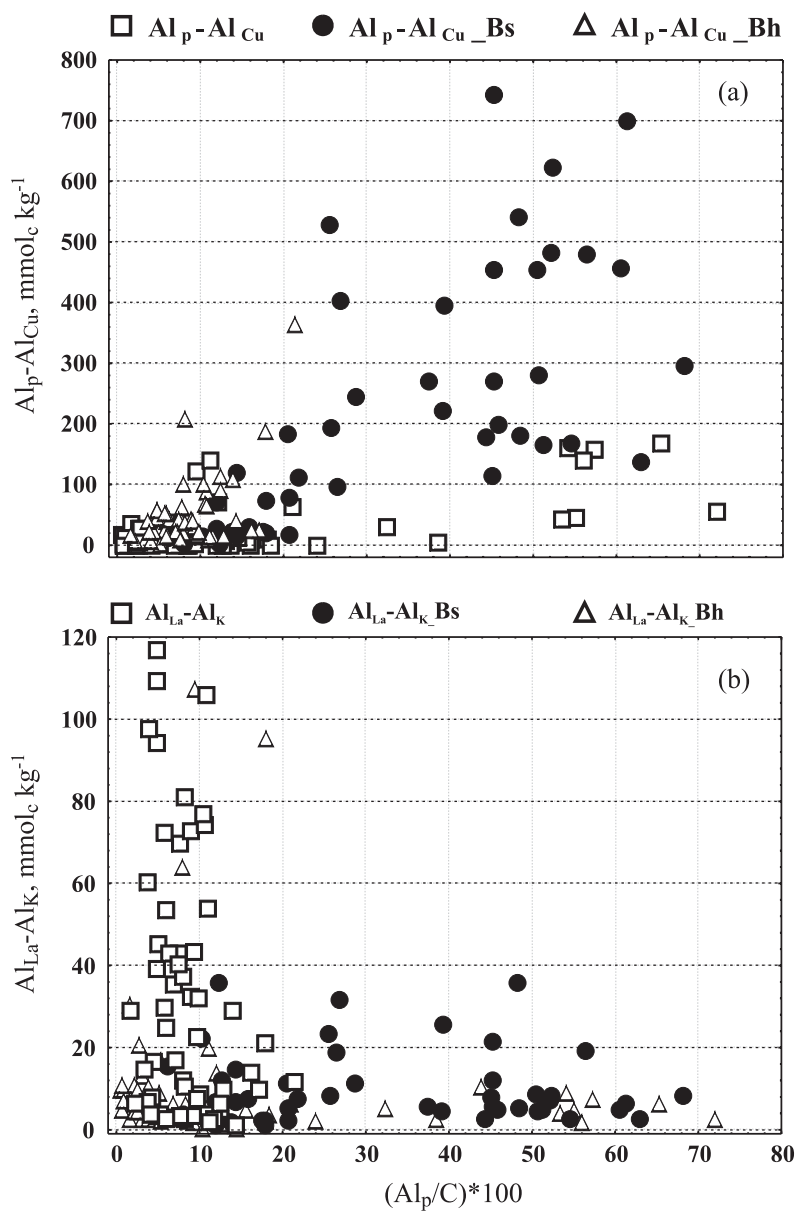

Figura 6. Relação entre a percentagem da saturação por $\mathrm{Al}$ no húmus $\left(\left(\mathrm{Al}_{\mathrm{p}} / \mathrm{C}\right) * 100\right)$ e as seguintes variáveis que expressam uma ordem decrescente da estabilidade da interação do $\mathrm{Al}$ com a matéria orgânica do solo (García-Rodeja et al., 2004): (a) $\mathrm{Al}_{\mathrm{p}}-\mathrm{Al}_{\mathrm{Cu}}$ e (b) $\mathrm{Al}_{\mathrm{La}}-\mathrm{Al}_{\mathrm{K}} \cdot \mathrm{Al}_{\mathrm{p}}-\mathrm{Al}_{\mathrm{Cu}-} \mathrm{Bh}$ e $\mathrm{Al}_{\mathrm{La}}-\mathrm{Al}_{\mathrm{K}} \mathrm{Bh}$ referem-se às amostras dos horizontes $\overline{\mathrm{Bh}}$ e $\mathrm{Bhm} ; \mathrm{Al}_{\mathrm{p}}-\mathrm{Al}_{\mathrm{Cu}-} \mathrm{Bs}_{\mathrm{e}} \mathrm{Al}_{\mathrm{La}}-\mathrm{Al}_{\mathrm{K}-} \mathrm{Bs}$, aos horizontes $\mathrm{Bs}$, Bhs e Bsm bem drenados; $\mathrm{Al}_{\mathrm{p}}$ $\mathrm{Al}_{\mathrm{Cu}}$ e $\mathrm{Al}_{\mathrm{La}}-\mathrm{Al}_{\mathrm{K}}$, aos demais horizontes estudados.

potencial redox, possivelmente tenham sido as principais responsáveis pela baixa disponibilidade e conteúdo do elemento nos solos estudados. No entanto, os extratores DC, oxalato e pirofosfato de sódio extraíram conteúdos similares para a maioria dos horizontes espódicos (Figura 7), o que sugere que o Fe está na forma predominantemente amorfa e unida à matéria orgânica, já que o DC é um extrator efetivo para óxidos de Fe livre nos solos sem discriminação de fases (Mehra \& Jackson, 1960; Farmer et al., 1983), enquanto o oxalato extrai a maior parte das formas amorfas de $\mathrm{Fe}$ e $\mathrm{Al}$, incluindo aquelas associadas ao húmus. Esta última é mais especificamente removida pelo reagente pirofosfato de sódio (McKeague, 1967; Farmer et al., 1983).

\section{Gênese dos Espodossolos}

Os valores de $\mathrm{Al}$ e Fe extraídos por ditionito-citrato $\left(\mathrm{Al}_{\mathrm{d}} ; \mathrm{Fe}_{\mathrm{d}}\right)$, oxalato $\left(\mathrm{Al}_{\mathrm{o}} ; \mathrm{Fe}_{\mathrm{o}}\right)$ e pirofosfato $\left(\mathrm{Al}_{\mathrm{p}}, \mathrm{Fe}_{\mathrm{p}}\right)$ apresentam clara tendência de acumulação nos horizontes iluviais (horizonte B) em relação aos horizontes A, E e C dentro de cada perfil. Essa tendência é acompanhada pela similar capacidade de extração desses reagentes (Figura 7), com relações $\mathrm{Al}_{0}$ / $\mathrm{Al}_{\mathrm{p}}$ e $\mathrm{Fe}_{\mathrm{p}} / \mathrm{Fe}_{\mathrm{d}}$ próximas a 1 (Quadro 1) para a maioria dos horizontes, sugerindo que o clássico mecanismo de mobilização, transporte e precipitação de complexos organometálicos na formação dos Espodossolos parece ser atuante nos perfis estudados, conforme amplamente relatado nos mais abrangentes e recentes estudos sobre o tema (Lumdström et al., 2000a,b; Buurman \& Jongmans, 2005; Jansen et al., 2005; Sauer et al., 2007). Assim, os horizontes espódicos foram formados predominantemente às expensas dos eluviais, os quais estão presentes em todos os Espodossolos estudados (Quadro 1).

Alumínio é o principal cátion envolvido na (i)mobilização da matéria orgânica, o que é evidenciado pela sua presença em todos os horizontes dos perfis, excetuando os eluviais (E; EA) e em quantidade geralmente muito superior à do $\mathrm{Fe}$, quando presente. Este último ocorre, predominantemente e em maiores conteúdos, nos Espodossolos e Neossolos Quartzarênicos bem drenados ou naqueles sujeitos a variações frequentes de drenagem, cujo conteúdo do elemento nas águas de drenagem e potenciais adequados de oxirredução foram favoráveis à sua

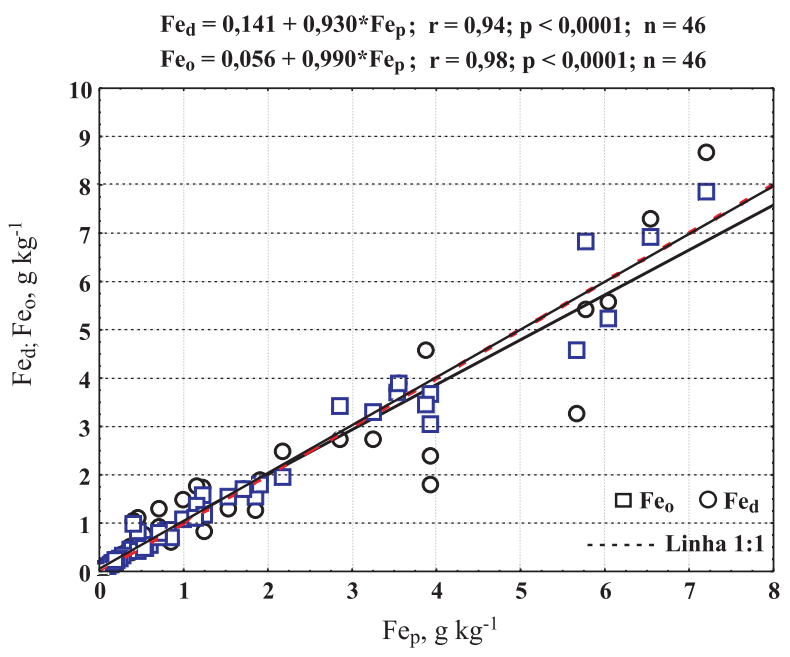

Figura 7. Relação entre os teores de Fe extraídos com pirofosfato $\left(\mathrm{Fe}_{\mathrm{p}}\right)$, ditionito $\left(\mathrm{Fe}_{\mathrm{d}}\right)$ e oxalato $\left(\mathrm{Fe}_{\mathrm{o}}\right)$ para os horizontes espódicos estudados e que apresentam conteúdos detectáveis do elemento pelas técnicas e diluições utilizadas. A proximidade das curvas de regressão em relação à linha 1:1, passando pela origem, evidencia que os extratores removeram conteúdos similares do elemento, o qual está predominantemente na forma orgânica $\left(\mathrm{Fe}_{\mathrm{p}}\right)$. 
precipitação; também está comumente presente nos horizontes superficiais, devido à ciclagem de nutrientes.

A tendência de aumento da relação $\mathrm{Al} / \mathrm{C}$ em profundidade para a maioria dos perfis estudados (Quadro 1) pode indicar que o principal mecanismo de imobilização dos complexos organometálicos está relacionado à incorporação adicional do $\mathrm{Al}$ durante sua iluviação no perfil (McKeague et al., 1978 citado por Sauer et al., 2007; De Coninck, 1980). Nesse mecanismo, o aumento da relação metal/carbono com a profundidade leva à precipitação pela formação de agregados maiores, originados da neutralização das cargas e polimerização da matéria orgânica iluviada (De Coninck, 1980).

É provável que os Espodossolos sob vegetação de restinga paulista tenham sido, em sua maioria, inicialmente formados sob condições de acentuado hidromorfismo, fato já genericamente relatado por van Breemen \& Buurman (2002) ao se referirem à gênese desses solos sob condições tropicais. Nesses ambientes, os complexos de Al-húmus predominam nos horizontes B espódicos, como relatado por Takahashi et al. (1995) e van Breemen \& Buurman (2002) e observado neste estudo, sendo que o Fe é perdido na sua forma reduzida (Anderson et al., 1982; Mokma \& Buurman, 1982; Farmer et al., 1983; Skjemstad et al., 1992b). A ocorrência deste último elemento, geralmente presente ou em maiores conteúdos nos horizontes Bs, Bhs e Bsm dos perfis bem drenados, a química e a mineralogia diferenciadas de algum desses horizontes em relação aos demais espódicos (Bh e Bhm) sugerem mecanismos diferenciados de pedogênese atuando nos perfis onde esses horizontes coexistem, possivelmente condicionados pelo hidromorfismo, que por sua vez está relacionado à dinâmica geológica/ sedimentar desses ambientes costeiros. Nesse contexto, os horizontes aqui identificados como Bs, Bhs e Bsm foram formados em condições de melhor drenagem em relação aos demais espódicos (Bh e Bhm) nos perfis onde eles coexistem.

\section{CONCLUSÕES}

1. A química da maioria dos solos de Bertioga, Ilha Comprida e Cananeia é semelhante à já descrita para as áreas sob vegetação de restinga do Estado de São Paulo: baixas soma e saturação por bases; extrema a fortemente ácidos; capacidade de troca de cátions dependente da matéria orgânica e dominada com $\mathrm{Al}$ trocável; e aumento do $\mathrm{C}$ em profundidade. Esses atributos refletem a influência tanto do material de origem como do processo pedogenético predominante nesses ambientes: a podzolização.

2. Alumínio é o principal cátion envolvido na podzolização, e suas formas ativas são: complexos de
Al-húmus e compostos inorgânicos pouco cristalinos. Os primeiros predominam nos horizontes superficiais e horizontes espódicos hidromórficos (Bh); as formas inorgânicas relacionam-se a alguns horizontes espódicos (Bs, Bhs e Bsm) situados na base de perfis mais bem drenados.

3. O conteúdo de Fe geralmente mostra-se em quantidade muito inferior à do $\mathrm{Al}$. Sua presença ou maiores conteúdos estão predominantemente associados à matéria orgânica nos horizontes superficiais e espódicos. Também ocorrem nos solos mais bem drenados ou naqueles sujeitos a hidromorfismo temporário. Nessas últimas condições, o potencial redox governa sua presença e forma no perfil, a qual é predominantemente inorgânica.

4. Há estreita relação entre a idade dos Espodossolos e os atributos químicos analisados: os mais antigos (Cananeia) diferenciam-se dos demais quer pelos maiores conteúdos médios de $\mathrm{C}$ e de $\mathrm{Al}$ ativo (Al trocável, Al oxalato e Al pirofosfato), quer pela maior estabilidade da interação Al-húmus nos horizontes espódicos. Inversamente, aqueles mais recentes, descritos e amostrados em Ilha Comprida, mostram seus horizontes espódicos com os menores conteúdos médios de $\mathrm{C}$ e de todas as formas de $\mathrm{Al}$ estudadas.

5. A queluviação de Al-húmus e sua imobilização em profundidade à medida que há saturação do elemento nos complexos organometálicos que migram no perfil parecem ser atuantes nos perfis estudados e responsáveis pela gênese dos horizontes espódicos e Espodossolos estudados.

\section{AGRADECIMENTOS}

À CAPES, pelo financiamento do doutoradosanduíche do primeiro autor (convênio CAPES/MECDDGU); à FAPESP, por meio do projeto "Solos sob vegetação de restinga no Estado de São Paulo: relações solo-paisagem, pedogênese e alterações com o uso agrícola", pelo apoio financeiro; e a Maria Santiso Taboada, técnica do laboratório da USC, pelo auxílio nas análises laboratoriais.

\section{LITERATURA CITADA}

ANDERSON, H.A.; BERROW, M.L.; FARMER, V.C.; HEPBURN, A.; RUSSEL, J.D. \& WALKER, A.D. A reassessment of podzol formation processes. J. Soil Sci., 33:125-136, 1982.

BLOOM, P.R.; MAcBRIDE, M.B. \& WEAVER, R.M. Aluminium organic matter in acid soils: Salt-extractable aluminum. Soil Sci. Soc. Am. J., 43:488-493, 1979. 
BUURMAN, P.; LAGEN, B. \& VELTHORST, E.J. Manual of soil and water analysis. Leiden, Backhuys Publishers Leiden, 1996. 314p.

BUURMAN, P. \& JONGMANS, A.G. Podzolization and soil organic matter dynamics. Geoderma, 125:71-83, 2005.

COELHO, M.R. Caracterização e gênese de Espodossolos da planície costeira do Estado de São Paulo. São Paulo, Universidade de São Paulo, 2008. 270p. (Tese de Doutorado)

COELHO, M.R.; MARTINS, V.M.; VIDAL-TORRADO, P.; SOUZA, C.R.G.; PEREZ, X.L.O. \& VÁSQUEZ, F.M. Relação solo-relevo-substrato geológico nas restingas da planície costeira do estado de São Paulo. R. Bras. Ci. Solo, 34:833-846, 2010a.

COELHO, M.R.; VIDAL-TORRADO, P.; PEREZ, X.L.O.; MARTINS, V.M. \& VÁSQUEZ, F.M. Fracionamento do alumínio por técnicas de dissoluções seletivas em Espodossolos da planície costeira do estado de São Paulo. R. Bras. Ci. Solo, 34:1081-1032, 2010b.

CHILDS, C.W.; PARFITT, R.L. \& LEE, R. Movement of aluminum as an inorganic complex in some podzolized soils, New Zealand. Geoderma, 29:139-155, 1983.

DE CONINCK, F. Major mechanisms in formation of spodic horizons. Geoderma, 24:101-126, 1980.

EMPRESA BRASILEIRA DE PESQUISA AGROPECUÁRIA EMBRAPA. Centro Nacional de Pesquisa em Solos. Sistema brasileiro de classificação de solos. 2.ed. Rio de Janeiro, 2006. 306p.

EMPRESA BRASILEIRA DE PESQUISA AGROCUPECUÁRIA - EMBRAPA. Centro Nacional de Pesquisa em Solos. Manual de métodos de análise de solo. 2.ed. Rio de Janeiro, 1997. $212 \mathrm{p}$

FARMER, V.C.; RUSSEL, J.D. \& SMITH, B.F.L. Extraction of inorganic forms of translocated $\mathrm{Al}, \mathrm{Fe}$ and $\mathrm{Si}$ from a podzol Bs horizon. J. Soil Sci., 34:571-576, 1983.

GARCÍA-RODEJA, E.; NÓVOA, J.C.; PONTEVEDRA, X.; MARTÍNEZ-CORTIZAS, A. \& BUURMAN, P. Aluminium fractionation of European volcanic soils by selective dissolution techniques. Catena, 56:155-183, 2004.

GOMES, F.H. Gênese e classificação de solos sob vegetação de restinga na Ilha do Cardoso-SP. São Paulo, Universidade de São Paulo, 2005. 107p. (Tese de Doutorado)

GOMES, J.B.V. Caracterização, gênese e uso dos solos de três sítios de restinga sob diferentes coberturas vegetais no estado do Rio de Janeiro. Viçosa, MG, Universidade Federal de Viçosa, 1995. 158p. (Tese de Mestrado)

GOMES, J.B.V.; RESENDE, M.; REZENDE, S.B. \& SÁMENDONÇA, E. Solos de três áreas de Restinga. I. Morfologia, caracterização e classificação. Pesq. Agropec. Bras., 33:1907-1919, 1998.

HARGROVE, W.L. \& THOMAS, G.W. Extraction of aluminumorganic matter complexes. Soil Sci. Soc. Am. J., 45:151$153,1981$.

HIGASHI, T. Characterization of $\mathrm{Al} / \mathrm{Fe}$-humus complexes in dustrandepts through comparison with synthetic forms. Geoderma, 31:277-288, 1983.
HOLMGREN, G.G.S. A rapid citrate-dithionite extractable iron procedure. Soil Sci. Soc. Am. Proc., 31:210-211, 1967.

JANSEN, B.; NIEROP, K.G.J. \& VERSTRATEN, J.M. Mechanisms controlling the mobility of dissolved organic matter, aluminium and iron in podzol B horizons. Europ. J. Soil Sci., 56:537-550, 2005.

JEANROY, E. \& GUILLET, B. The occurrence of suspended ferruginous particles in pyrophosphate extracts of some soil horizons. Geoderma, 26:95-106, 1981.

JUO, A.S. \& KAMPRATH, E.J. Cooper chloride as an extractant for estimating the potentially reactive aluminium pool in acid soils. Soil Sci. Soc. Am. J., 43:35$38,1979$.

KAISER, K. \& ZECH, W. Defects in estimation of aluminum in humus complexes of podzolic soils by pyrophosphate extraction. Soil Sci., 161:452-458, 1996.

LUMDSTRÖM, U.S.; van BREEMEN, N. \& BAIN, D. The podzolization process. A review. Geoderma, 94:91-107, 2000a.

LUMDSTRÖM, U.S.; van BREEMEN, N.; BAIN, D.; van HEES, P.A.W.; GIESLER, R.; GUSTAFSSON, J.P.; ILVESNIEMI, H.; KARLTUN, E.; MELKERUD, P.A., OLSSON, M.; RIISE, G.; WAHLBERT, O.; BERGELIN, A.; BISHOP, K.; FINLAY, R.; JONGMANS, A.G.; MAGNUSSON, T.; MANNERKOSKI, H.; NORDGREN, A.; LYBERG, L.; STARR, M. \& TAU-SATRAND, L. Advances in understanding the podzolization process resulting from a multidisciplinary study of three coniferous forest soils in the Nordic Countries. Geoderma, 94:335-353, 2000b.

McKEAGUE, J.A. An evaluation of 0,1 M pyrophosphate and pyrophosphate-dithionite in comparison with oxalate as extractant of the accumulation products in podzols and some other soils. Can. J. Soil Sci., 46:12-22, 1967.

McKEAGUE, J.A.; BRYDON, J.E. \& MILES, N.M. Differentiation of forms of extractable iron and aluminum in soils. Soil Sci. Soc. Am. Proc., 35:33-38, 1971.

MARTINS, V.M. Relação solo-relevo-substrato geológico na planície costeira sedimentar de Bertioga - SP. São Paulo, Universidade de São Paulo, 2009. 273p. (Tese de Doutorado)

MEHRA, O.P. \& JACKSON, M.L. Iron oxide removal from soils and clays by dithionite-citrate system buffered with sodium bicarbonate. Clays Clay Miner., 7:317-327, 1960.

MELO, M.R.F. \& MANTOVANI, W. Composição florística e estrutura fitssociológica da mata atlântica de encosta na Ilha do Cardoso (Cananéia, SP, Brasil). B. Inst. Bot., 9:107158, 1994.

MOKMA, L. \& BUURMAN, P. Podzols and podzolization in temperate regions. Wageningen, International Soil Museum, 1982. 126p. (ISM monograph, 1)

MOKMA. L. New chemical criteria for defining the spodic horizon. Soil Sci. Soc. Am. J., 47:972-976, 1983.

MOREIRA, M.G. Associações entre os solos, os ambientes sedimentares quaternários e as fitofisionomias de planície costeira e baixa encosta nas Bacias dos Rios Itaguaré e Guaratuba (Bertioga-SP). São Paulo, Instituto de Botânica da Secretaria de Estado do Meio Ambiente, 2007. 157p. (Tese de Mestrado) 
OATES, K.M. \& KAMPRATH, E.J. Soil acidity and liming: II. Evaluation of using aluminum extracted by various chloride salts for determining lime requirements. Soil Sci. Soc. Am. J., 47:690-692, 1983.

NASCIMENTO JÚNIOR, D.R. Morfologia e sedimentologia ao longo do sistema praia - duna frontal de Ilha Comprida, SP. São Paulo, Instituto de Geociências, 2006. 97p. (Tese de Mestrado)

OLIVEIRA, J.B.; JACOMINE, P.K.T. \& CAMARGO, M.N. Classes gerais de solos do Brasil: Guia auxiliar para seu reconhecimento. 2.ed. Jaboticabal, FUNEP, 1992. 201p.

PAGÉ, C.R. \& KIMPE, C.R. Dissolution des composes ferrugineux et alimineux des horizons B podzoliques de sols du Quebec par de dithionite-citrate, l'oxalate, le pyrophosphate et le tetraborate. Canadian J. Soil Sci., 69:451-459, 1989.

PARFITT, R.L. \& CHILDS, C.W. Estimation of forms of Fe and $\mathrm{Al}$ : A review, and analysis of contrasting soils by dissolution and Mossbauer methods. Austr. J. Soil Res., 26:121-144, 1988.

PATERSON, E.; CLARK, L. \& BIRNIE, C. Sequential selective dissolution of iron, aluminium, and silicon from soils. Comm. Soil Sci. Plant Anal., 24:2015-2023, 1993.

PETRI, S. \& FÚLFARO, V.J. Nota sobre a geologia e terraços marinhos da Ilha do Cardoso. Notícias Geomorfol., 10:21 31, 1970.

RAIJ, B.van; ANDRADE, J.C.; CANTARELLA, H. \& QUAGGIO, J.A. Análise química para avaliação da fertilidade de solos tropicais. Campinas, Instituto Agronômico de Campinas, 2001. 285p.

ROSSI, M. Fatores formadores da paisagem litorânea: A bacia do Guaratuba, São Paulo, Brasil. São Paulo, Universidade de São Paulo, 1999. 168p. (Tese de Doutorado)

SANTOS, R.D.; LEMOS, R.C.; SANTOS, H.G.; KER, J.C. \& ANJOS, L.H.C. Manual de descrição e coleta de solo no campo. 5.ed. Viçosa, MG, Sociedade Brasileira de Ciência do Solo, 2005. 100p.

SAUER, D.; SPONAGEL, H.; SOMMER, M.; GIANI, L.; JAHN, R. \& STAHR, K. Review article - Podzol: Soil of the year 2007 - A review on its genesis, occurrence, and functions. J. Plant Nutr. Soil Sci., 170:581-597, 2007.

SCHUPPLI, P.A.; ROSS, G.J. \& McKEAGUE, J.A. The effective removal of suspended materials from pyrophosphate extracts of soils from tropical and temperate regions. Soil Sci. Soc. Am. J., 47:1026-1032, 1983.
SHOJI, S. \& FUJIWARA, Y. Active aluminum and iron in the humus horizons of Andosols from northeastern Japan: Their forms, properties and significance in clay weathering. Soil Sci., 137:216-226, 1984.

SHOJI, S.; FUJIWARA, Y.; YAMADA, I. \& SAIGUSA, M. Chemistry and clay mineralogy of Ando soils, Brown forest soils, and Podzolic soils formed from recent Towada ashes, Northeastern Japan. Soil Sci., 133:69-86, 1982.

SKJEMSTAD, J.O.; WATERS, A.G.; HANNA, J.V. \& OADES, J.M. Genesis of Podzols on Coastal Dunes in Southern Queensland. II. Nature of the organic fraction as seen by ${ }^{13} \mathrm{C}$ nuclear magnetic resonance spectroscopy. Austr. J. Soil Res., 30:615-644, 1992a.

SKJEMSTAD, J.O.; FITZPATRICK, R.W.; ZARCINAS, B.A. \& THOMPSON, C.H. Gênesis of Podzols on Coastal Dunes in Southern Queensland. II. Geochemistry and forms of elements as deduced from various soil extraction procedures. Austr. J. Soil Res., 30:615-644, 1992b.

SUGUIO, K \& MARTIN, L. Formações quaternárias marinhas do litoral paulista e sul fluminense. In: INTERNATIONAL SYMPOSIUM ON COASTAL EVOLUTION IN THE QUATERNARY, 1978a, São Paulo. Anais...São Paulo, IGCB/IG-USP/SBG, 1978a. 55p. (Special Publication, 1)

SUGUIO, K. \& MARTIN, L. Mapa geológico do litoral de São Paulo, Escala 1:100.000. Folha de Bertioga, São Paulo, Secretaria de Obras e Meio Ambiente/Departamento de Águas e Energia Elétrica, 1978b.

SUGUIO, K.; TATUMI, S.H. \& KOWATA, E.A. The comprida island inactive dune ridges and their possible significance for the island evolution during the Holocene, State of São Paulo, Brazil. An. Acad. Bras. Ci., 71:623-630, 1999.

SUGUIO, K. \& TESSLER, M.G. Planícies de cordões litorâneos quaternários do Brasil: Origem e nomenclatura. In: LACERDA, L.D.; ARAÚJO, D.S.D.; CERQUEIRA, R. \& TURQ, B. Restingas: Origem, estrutura e processos. Niterói, CEUFF, 1984. p.15-26.

TAKAHASHI, T.; FUKUOKA, T. \& DAHLGREN, R.A. Aluminum solubility and release rates from soil horizons dominated by aluminum-humus complexes. Soil Sci. Plant Nutr., 41:119-131, 1995.

van BREEMEN, N. \& BUURMAN, P. Soil formation. 2.ed. Dordrecht, Kluwer Academic Publishers, 2002. 404p.

VILLWOCK, J.A.; LESSA, G.C.; SUGUIO, K.; ANGULO, R.J. \& DILLENBURG, S.R. Geologia e geomorfologia de regiões costeiras. In: SOUZA, C.R.G.; SUGUIO, K.; OLIVEIRA, A.M.S. \& OLIVEIRA, P.E., eds. Quaternário do Brasil. Ribeirão Preto, Holos, 2005. p.94-113. 